\title{
Was bedeutet Religion für Rechtsextremismus? Empirische Befunde zu Verbindungen zwischen Religiosität, Vorurteilen und rechtsextremen Einstellungen
}

\author{
Verena Schneider (D) - Gert Pickel 1 - Cemal Öztürk
}

Eingegangen: 25. Januar 2021 / Überarbeitet: 30. Juni 2021 / Angenommen: 6. Juli 2021 / Online publiziert: 17. August 2021

(C) Der/die Autor(en) 2021

Zusammenfassung Zunehmend machen rechtspopulistische und rechtsextreme Akteur:innen in Deutschland und Europa ,,den Islam“ oder „,die Muslime“ für das Entstehen gesellschaftlicher Konflikte verantwortlich. Diese Entwicklung begann spätestens mit dem 11. September 2001 und wurde durch die Fluchtbewegungen nach Europa 2015 zusätzlich verstärkt. Als Feindbild dienen rechten Akteur:innen neben Muslim:innen auch Jüd:innen. Sowohl bei Muslimfeindlichkeit als auch bei Antisemitismus fungiert die Religionszugehörigkeit als Ablehnungsmarker, den Rechtsextreme und Rechtspopulist:innen zur Mobilisierung nutzen. Auf der anderen Seite könnte sich auch Religiosität auf Seiten der Mehrheitsgesellschaft auf die Ausbildung rechtsextremer Einstellungen auswirken. Hierbei könnten zudem Vorurteile gegenüber Frauen sowie Menschen mit einer nicht-binären Geschlechtsidentität eine Rolle spielen. Doch wie genau hängen Religion, Vorurteile und Rechtsextremismus miteinander zusammen? Anhand von Umfragedaten zeigen die Autor:innen zunächst Korrelationen zwischen Rechtsextremismus, Muslimfeindlichkeit und Antisemitismus auf. Weiter stellen sie die ambivalente Wirkung von Religiosität heraus Während eine dogmatisch-fundamentalistische Religionsauslegung sowie Esoterikglauben rechtsextreme Einstellungen befördern, wirkt eine soziale Religiosität - also die Kombination von religiösem mit sozialem Engagement - extrem rechten Haltungen entgegen. Abschließend erklären die Autor:innen die Brückenfunktion von Vorurteilen gegenüber Muslim:innen und Jüd:innen sowie gegenüber Ausländer:innen,

\footnotetext{
Verena Schneider $(\bowtie) \cdot$ Gert Pickel Universität Leipzig, Leipzig, Deutschland

E-Mail: verena.schneider@uni-leipzig.de

Gert Pickel

E-Mail: pickel@rz.uni-leipzig.de

Cemal Öztürk

Universität Duisburg-Essen, Duisburg, Deutschland

E-Mail: cemal.oeztuerk@uni-due.de
} 
Geflüchteten, Sinti:zze und Rom:nja, Frauen und Menschen mit nicht-binärer Geschlechtsidentität: Abwertende Haltungen gegenüber all diesen Gruppen können als „Scharnier“ hin zu rechtsextremen Vorstellungswelten dienen.

Schlüsselwörter Religion · Vorurteile $\cdot$ Rechtsextremismus · Rechtspopulismus · Rassismus · Muslimfeindlichkeit · Antisemitismus · Fundamentalismus · Esoterik · Soziale Religiosität · Gesellschaftlicher Zusammenhalt

\title{
What does religion mean for right-wing extremism? Empirical findings on links between religiosity, prejudice and extreme right-wing attitudes
}

\begin{abstract}
German and European right-wing populists and extremists increasingly blame "Islam" or "the Muslims" for the emergence of societal conflicts. This development started, at the latest, with 9/11 and was reinforced by the refugee movements towards Europe in 2015. Muslims, along with Jews, are seen as the enemy. In Islamophobia as well as in antisemitism, religious adherence functions as a marker of rejection around which right-wing extremists and populists mobilize. On the other hand, religiosity on behalf of the social majority might also impact the formation of right-wing extremist attitudes. Prejudice against women and people with non-binary gender identities might play a role in this aspect. How exactly are religion, prejudice, and right-wing extremism related? By means of survey data, the authors first show correlations between right-wing extremism, Islamophobia, and antisemitism. Additionally, they explain the ambivalent role of religiosity: While dogmatic, fundamentalist religious beliefs as well as esotericism promote extremist attitudes, a social religiosity - that is, combining religious with social commitment-counteracts them. In conclusion, the authors explain the bridging function of prejudice against Muslims and Jews as well as against foreigners, refugees, Sinti and Romanies, women, and people with non-binary gender identities: Depreciating attitudes towards all of these groups can serve as a gateway to a right-wing worldview.
\end{abstract}

Keywords Religion · Prejudice - Right-wing extremism - Right-wing populism • Racism · Islamophobia $\cdot$ Antisemitism $\cdot$ Fundamentalism $\cdot$ Esotericism $\cdot$ Social religiosity $\cdot$ Social cohesion 


\section{Einleitung: Rechtsextremismus und Religion - eine mögliche Beziehung?}

Rechtsextremismus stellt für die existierenden Demokratien in Europa ein Problem dar. ${ }^{1}$ Nicht nur wird er als zentraler Gegner der Demokratie angesehen, er beinhaltet auch rassistische Diskriminierung, Vorstellungen von Ungleichwertigkeit und Gewalt. Wenig überraschend liegen vielfältige Studien und Publikationen zu den Auswirkungen und Gründen des Rechtsextremismus vor (u. a. Arzheimer 2008; Kailitz 2004; Minkenberg 2000, 2011; Mudde 2019; Norris 2005; Quent 2019; Rydgren 2018; Virchow et al. 2016). Dies trifft, in etwas geringerem Umfang, auch auf Studien zu rechtsextremen Einstellungen zu (Decker und Brähler 2018, 2020). Zudem ist in den letzten Jahrzehnten ein Wiederaufleben rechtsextremer Rhetorik und Sichtbarkeit festzustellen. Oft wird letzteres in Relation zum Aufkommen des sogenannten Rechtspopulismus gesehen, der - je nach Lesart - als eigenständiges Phänomen, abgemilderte Variante oder öffentlichkeitstaugliche Form des Rechtsradikalismus verstanden wird. Wie auch immer, Debatten um Rechtsextremismus und rechtsextreme Einstellungen sind wieder stärker in den Blick von Öffentlichkeit und Wissenschaft gerückt (Arzheimer 2019).

Der Faktor Religion wird in diesen Zusammenhängen zwar genannt, spielt aber in der Regel eine untergeordnete Rolle, selbst wenn bei Darstellungen von Rassismus der antimuslimische Rassismus eine zunehmend prominente Position einnimmt und der Antisemitismus teilweise als dem Rechtsextremismus immanente Komponente angesehen wird (Salzborn 2014; Wiedemann 2016). Die engen Verbindungen zwischen Rechtsextremismus und Rassismus gerade gegenüber religiös definierten Gruppen sprechen für eine wachsende Relevanz des Faktors Religion im Forschungsfeld Rechtsextremismus. ${ }^{2}$ Diese Relevanz wird auch an dem im Herbst 2020 beschlossenem Maßnahmenpaket gegen Rechtsextremismus und Rassismus durch die Bundesregierung, die Einsetzung einer unabhängigen Expertenkommissionen zu Muslimfeindlichkeit oder die Etablierung von Antisemitismusbeauftragten in immer mehr Bundesländern zum Ausdruck gebracht. Dies liegt auch nahe, wird doch seitens rechtsextremer und rechtspopulistischer Akteur:innen zunehmend ,der Islam“ oder „die Muslime“ als die zentrale Ursache von Konflikten in den euro-

\footnotetext{
${ }^{1}$ Der vorliegende Text entstand im Rahmen des von Prof. Dr. Susanne Pickel an der Universität Duisburg-Essen geleiteten BMBF-Projektverbundes „Radikaler Islam versus Radikaler Anti-Islam“ sowie im Rahmen des BMBF geförderten Forschungsprojektes „Politischer Kulturwandel? Legitimität der Demokratie und gesellschaftlicher Zusammenhalt in Zeiten verstärkten Populismus und steigender Islamablehnung“ im Forschungsinstitut Gesellschaftlicher Zusammenhalt, Projektkennung: LEI_F_08. Zudem werden aktuelle Umfragedaten aus dem gemeinsamen Deutsch-Schweizer Projekt „Konfigurationen individueller und kollektiver religiöser Identitäten und ihre zivilgesellschaftlichen Potentiale" (KONID), das seit 2018 durchgeführt wird, verwendet. Ziel des Teilprojektes des Forschungsverbundes „Soziale Gruppen und religiöse Identitäten in ziviler Gesellschaft" (RESIC) ist es, Aussagen über religiöse Identitäten zu erzielen. Projektleiter sind Prof. Dr. Gert Pickel (Leipzig) und Prof. Dr. Antonius Liedhegener (Luzern). Weitere Informationen zu diesem Projekt sowie neue Veröffentlichungen finden sich unter https://resic. info/. Das Projekt ist gefördert von der Deutschen Forschungsgemeinschaft (DFG) und dem Schweizer Nationalfonds (SNF). Siehe zu ersten Ergebnissen auch Liedhegener et al. (2019). Wir danken für die Förderungen seitens der DFG und seitens des BMBF.

2 https://www.tagesschau.de/inland/ausschuss-rechtsextremismus-103.html.
} 
päischen Gesellschaften und als Gefährdung des gesellschaftlichen Zusammenhalts ausgemacht (Pickel und Pickel 2018b; Pickel et al. 2020a, S. 230-244). Die Wertvorstellungen ,des Islam“ werden als mit christlichen bzw. westlichen Werten genauso unvereinbar wahrgenommen wie seiner „Kultur“ (Shooman 2014), und daraus wird die Konsequenz gezogen, sich strikt gegen die Einwanderung von Muslim:innen zu positionieren (Küpper und Zick 2010; Pickel und Yendell 2016; Schönfeld 2018; Zick et al. 2019). Doch nicht nur Muslim:innen stellen ein hilfreiches Feindbild von Rechtsextremist:innen dar, auch der für den Rechtsextremismus konstitutive Antisemitismus hat in der Neuzeit nicht aufgehört zu bestehen. Manche gehen sogar davon aus, dass er einen neuen Schub in Form eines ,neuen Antisemitismus“ erhalten hat (z. B. Heilbronn et al. 2019; Lipstadt 2019).

Ob neu oder althergebracht, es lässt sich beobachten, dass Rechtspopulist:innen und Rechtsextremist:innen die Ablehnung bestimmter Religionsgruppen strategisch als Orientierungspunkt für ihre Aktionen und als Mobilisierungshilfe nutzen (Rippl und Seipel 2018). Bei der Durchsetzung ihrer politischen Ideologie eines homogenisierten Nativismus dringen sie über die Aktivierung von in der Bevölkerung bestehenden antimuslimischen und antisemitischen Einstellungen bis in die Mitte der Gesellschaft vor (Decker und Brähler 2006, Decker et al. 2016; Pickel et al. 2020d). Sie knüpfen an unterschiedliche Ausformungen von Ressentiments (z.B. primärer Antisemitismus, sekundärer Antisemitismus, Antijudaismus, neuer Antisemitismus, israelbezogener Antisemitismus) an. Gelegentlich werden sogar antimuslimische und antisemitische Feindbilder verknüpft, wie im Verschwörungsmythos der ,großen Umvolkung“ (z. B. Butter 2018, S. 167-169). Dort wird erzählt, dass ein finanzstarkes Judentum daran arbeite, die europäische Bevölkerung durch gezielt geförderte muslimische Zuwanderung zu ersetzen. Religionsgemeinschaften scheinen also ein wichtiges Zielobjekt für rechte Akteur:innen zu sein.

Religion ist allerdings nicht nur auf der Seite der betroffenen Religionsgemeinschaften von Interesse. Es stellt sich auch die Frage, inwieweit Religiosität oder eine bestimmte Form von Religiosität sich als förderlich für rechtsextreme Einstellungen erweist. Nicht rein zufällig rufen Rechtspopulist:innen, Verschwörungsmytholog:innen und Rechtsextremist:innen gerne zur „Verteidigung des christlichen Abendlandes“ auf. Hier wird auf religiöse Identitäten und Verständnisse spekuliert, die zumindest eine „Wahlverwandtschaft“" von Christ:innen zu rechten Themen und Überzeugungen stiften soll. So verwies z.B. 2018 das Forschungsinstitut PEW auf überdurchschnittlich migrantenunfreundliche Haltungen unter Kirchgänger:innen und religiösen Menschen (PEW 2018, S. 21-24, zur Diskussion der Ergebnisse auch Pickel 2018, S. 279), Michael Lühmann thematisierte kritisch die Vorurteile im deutschen „Bible Belt“ (Lühmann 2020), oder Liane Bednarz (2018) sah eine Gefahr für die Demokratie in rechten „Angstpredigern“. Neben einer potenziellen Ablehnung anderer Religionsgemeinschaften werden dabei auch Vorurteile gegenüber verschiedenen anderen sozialen (nicht nur religiösen) Gruppen (z. B. Frauen, Homosexuelle, Transgender) als Mobilisierungspotenzial von Christ:innen durch Rechtspopulist:innen und Rechtsextreme ausgemacht (Pickel et al. 2020b, S. 184). Z. B. wird gerade die Unzufriedenheit mit und die Ablehnung von nicht-binär-heterosexuellen Partnerschaften oder des Feminismus als Gemeinsamkeit zwischen 
Personen und Parteien des rechten Randes einerseits und konservativen Christ:innen andererseits herausgestellt (Höcker et al. 2020, S. 260, 273-274).

Auf der anderen Seite gibt es Hinweise auf einen Vorurteile und rechtsextreme Orientierungen abbauenden Effekt einer liberalen Religiosität (Lesch 2017; Pickel et al. 2020b, c). Huber und Yendell (2019, S. 74) weisen sogar auf einen immunisierenden Effekt von Religiosität hinsichtlich rechtsextremer Einstellungen hin, der sich vor allem in Ostdeutschland zeige (auch Backes und Kailitz 2020). Und waren es nicht gerade Kirchenmitglieder, die im Umfeld der Fluchtbewegungen 2015 in großer Zahl Betreuungsmöglichkeiten für Geflüchtete aufbauten und betreuten? Zudem finden sich im Umfeld der christlichen Kirchen vielfältige Bewegungen gegen „Rechts“, die dem Bild einer generell größeren Offenheit von Christ:innen für rechte Rhetorik widersprechen. Insgesamt kommt man damit zu einem ambivalenten Bild, das schon in frühen Forschungen auftaucht (Adorno 1973; Allport 1979).

Um dieser Widersprüchlichkeit auf die Spur zu kommen, möchten wir uns in diesem Beitrag den folgenden beiden Forschungsfragen widmen: (1) Bestehen Zusammenhänge zwischen Religion bzw. Religiosität und rechtsextremen Einstellungen? (2) Welche Wirkung besitzen Religiosität und Religionszugehörigkeit auf rechtsextreme Einstellungsmuster? Antworten auf die Fragen versuchen wir mit Hilfe von Analysen repräsentativer Umfragen zu gewinnen.

\section{Konzeptionelle Überlegungen zum Verhältnis von Religion und Rechtsextremismus}

Will man die Bedeutung von Religion für Rechtsextremismus bestimmen, so benötigt man zuerst eine Definition von Rechtsextremismus. Hier existiert ein Bündel an unterschiedlichen Definitionen (Neureiter 1996, S. 12-21; Salzborn 2015, S. 14-19; Virchow 2016, S. 13-20). Nicht selten münden diese Versuche in der Bezeichnung des Rechtsextremismus als Syndrom oder Sammelphänomen von verschiedenen Elementen (Pfahl-Traughber 2019, S. 29-42). Eine relativ breit anerkannte Definition, die die zentralen Aspekte der Bezeichnung von Rechtsextremismus beinhaltet, ist die von Hans-Gerd Jaschke (2001). Er definiert Rechtsextremismus mit folgenden Worten:

Unter „Rechtsextremismus“ verstehen wir die Gesamtheit von Einstellungen, Verhaltensweisen und Aktionen, organisiert oder nicht, die von der rassisch oder ethnisch bedingten sozialen Ungleichheit der Menschen ausgehen, nach ethnischer Homogenität von Völkern verlangen und das Gleichheitsgebot der Menschenrechts-Deklaration ablehnen, die den Vorrang der Gemeinschaft vor dem Individuum betonen, von der Unterordnung des Bürgers unter die Staatsräson ausgehen und die den Wertepluralismus einer liberalen Demokratie ablehnen und Demokratisierung rückgängig machen wollen. (Jaschke 2001, S. 30)

Rechtsextremismus beruht der Definition nach vor allem auf der Annahme der Ungleichwertigkeit von Menschengruppen. Diesen Aspekt stellt auch Wilhelm Heitmeyer (1992, S. 15-18) in den Vordergrund seiner Untersuchungen zur „Gruppenbezogenen Menschenfeindlichkeit“", die er als zentrale Einstiegseinstellung zum 
Rechtsextremismus ausmachte. Die als ungleichwertig angesehenen Gruppen können dabei ganz unterschiedlich konstruiert werden, am deutlichsten ist allerdings die Abgrenzung gegenüber kulturell oder identitär als fremd angesehenen Gruppen. So geriert sich der Rechtsextremismus als stark mit nationalistischen und national-chauvinistischen Überzeugungen verbunden. Diese ethnozentristische Vorstellung bringt Rechtsextremist:innen in einen quasi unauflösbaren Gegensatz zu allen Entwicklungen der Pluralisierung - und damit auch in eine antidemokratische Position (auch Falter 1994, S. 138; Pfahl-Traughber 2019). ${ }^{3}$ In Kombination mit einer Vorliebe für eine starke Führungspersönlichkeit sowie einem ausgeprägten Antisemitismus wie Rassismus schließt der Rechtsextremismus, teils gezielt, an die Ideologie des Faschismus an (Beyer und Schnabel 2019, S. 12). Rassistische Elemente, die Zuschreibung von Ungleichwertigkeit auf andere sozialen Gruppen, Vorurteile gegenüber von der eigenen homogenen Norm abweichenden sozialen Gruppen sowie ein antipluralistischer, antidemokratischer und ethnozentristischer Nationalismus kennzeichnen den Rechtsextremismus. In weicherer Form findet sich diese Ideologie übrigens im Rechtspopulismus wieder, wobei die Grenzen zwischen Rechtsextremismus und Rechtspopulismus gelegentlich verschwimmen (Neureiter 1996, S. 22-24; Mudde 2019, S. 7-8; Priester 2012, S. 164, 185; Virchow 2016, S. 19).

Rechtsextremist:innen unterschieden sich von Rechtspopulist:innen oder Rechtsradikalen durch ihre klare Positionierung gegen die Demokratie und analytisch durch ihre Verfassungsfeindlichkeit. Damit löste in den 1970er-Jahren der Begriff Rechtsextremismus in den Überlegungen des Verfassungsschutzes den des Rechtsradikalismus $\mathrm{ab}$, der ebenfalls eine grundlegende Positionierung gegen den Staat und die herrschende Ordnung beschrieb (Pickel und Decker 2016, S. 10-14). Der Rechtspopulismus als Bezeichnung erfuhr in den letzten Jahrzehnten, nach einer frühen Genese in den 1920er-Jahren in den USA und einem folgenden Zwischenhoch in Lateinamerika, einen Aufschwung (Jörke und Selk 2017, S. 17-31). Er kann sowohl als Politikstil mit dem Ziel des Machterwerbs oder eben als Ideologie einer Spaltung zwischen ,Volk und Eliten“" verstanden werden (Priester 2012, S. 40-44; Mudde und Rovira Kaltwasser 2017, S. 1-20; Taggart 2000, S. 10-23; Urbinati 2019). Egal, wie man ihn sieht, wird er doch als noch verfassungsgerechte Variante angesehen, die sich aber immer wieder durch Grenzüberschreitungen hin zu rechtsextremen Aussagen und Positionen als für die Demokratie durchaus bedrohlich zeigt. Entsprechend finden sich viele Vorurteile nicht nur bei Rechtsextremist:innen, sondern auch bei Rechtspopulist:innen, von deren Position aus der Weg in den Rechtsextremismus nicht mehr so weit ist (Priester 2007). Cas Mudde fasst dementsprechend in neueren Schriften oft beide Formen unter der ,radical right“ zusammen (Mudde 2019). Dabei ist es aufgrund der Fluidität des Rechtspopulismus schwieriger, rechtspopulistische als rechtsextreme Einstellungen zu analysieren, da erstere bislang kein von allen Forscher:innen akzeptiertes und klar abgrenzbares Mind-Set aufweisen. Im vorliegenden Beitrag wird der Blick auf rechtsextreme Einstellungen gerichtet.

\footnotetext{
3 In neuerer Zeit versuchen Rechtspopulist:innen und Anhänger:innen der „Neuen Rechten“, diese Position zu entschärfen. Dafür greifen sie auf einen Ethnopluralismus zurück, der im ersten Moment nicht das Lebensrecht anderer Ethnien und sozialer Gruppen leugnet, aber in konsequenter nationalistischer Weiterführung deren Lebensrecht auf ihre „Heimatgebiete“ beschränkt.
} 
Nicht selten gelten die Befunde aber in Teilen auch für breitere Teile des rechten Spektrums wie Rechtspopulist:innen, weswegen letztere immer einmal wieder mit genannt werden.

Zur Erklärung des Aufkommens oder Florierens des Rechtsextremismus existiert eine ganze Bandbreite an Erklärungsansätzen (Neureiter 1996, S. 138-272). Startend mit der Wahrnehmung des Rechtsextremismus als „,normale Pathologie“ moderner Industriegesellschaften (Scheuch und Klingemann 1967, S. 12; auch Salzborn 2015, S. 94-95) seien hier nur die Ansätze der Autoritarismustheorie (auf die wir später noch einmal zurückkommen werden) und die Thesen der Modernisierungsverlierer:innen, der politischen Deprivation oder des „Extremismus der Mitte“ genannt (Decker und Brähler 2006; Gurr 1973; S. 101; Lipset 1981; Spier 2010). In jüngerer Zeit richtete sich dabei das Augenmerk auf die Messung rechtsextremer Einstellungen. Rechtsextreme Einstellungen sind dabei nicht mit rechtsextremistisch motivierten Taten gleichzusetzen, gehen ihnen allerdings in der Regel voraus. Wenn man rechtsextreme Einstellungen betrachtet, dann geht es also um die Haltungen der Bevölkerung zu entsprechenden Themen - und deren potenzielle Mobilisierbarkeit für eine rechte politische Ideologie. Nach einer längeren Periode je nach Forscher:in variierender Messungen von rechtsextremen Einstellungen, die durch ihre unterschiedlichen Befunde Misstrauen an der politisch sensiblen Erhebung nach sich zogen, einigte sich Anfang dieses Jahrhunderts eine sogenannte Konsensgruppe auf eine überwiegend einheitliche Messung rechtsextremer Einstellungen. Das Syndrom rechtsextremer Einstellungen wurde dabei als „sozial geteilte Ideologien im Sinne eines generalisierten Einstellungsmusters" verstanden, die neben der Befürwortung einer rechtsautoritären Diktatur auch nationalistischen Chauvinismus, Fremdenfeindlichkeit, Antisemitismus, Verharmlosung des Nationalsozialismus sowie die generelle Ungleichwertigkeitsvorstellung des Sozialdarwinismus beinhalten (Zick und Küpper 2016, S. 90-92; Decker und Brähler 2006, S. 20-21).

Für unseren Beitrag zentral ist die Verbindung von rechtsextremen Einstellungen mit Religion und Religiosität. Interessanterweise ist die Zahl der vorliegenden Arbeiten hierzu begrenzt. In der klassischen Rechtsextremismusforschung spielen religiöse Aspekte nur eine nachgeordnete Rolle. So wird gelegentlich auf die Nähe extrem rechter Weltdeutungen zu neuheidnischen Denkweisen rekurriert (Schnurbein 1992; zusammenfassend Virchow 2016, S. 11) oder mit Rekurs auf Gedanken Eric Voegelins (1938) an die Debatten zu ,politischen Religionen“ als Pendant rechter Ideologie oder eines rechten Totalitarismus angeschlossen (Backes und Jesse 1995; Strube 2015). Diese Zugriffe zeichnen sich allerdings entweder durch eine begrenzte Reichweite oder aber eine Begriffsdiskussion in Anschluss an Theorien zum Faschismus aus. Neuere Arbeiten nehmen den Begriff der Weltanschauungen auf, um den Zusammenhang zwischen religiösen Sichtweisen und politischen Überzeugungen aufzuzeigen (Beyer und Schnabel 2019). Vor dem Hintergrund dieser begrenzten konzeptionellen Diskussion der Wirkungen von Religiosität oder Religionszugehörigkeit auf rechtsextreme Einstellungen ist es nicht überraschend, dass Religion und Religiosität in der empirischen Erforschung von rechtsextremen Einstellungen lange eine Nebenrolle einnahmen. Erst in jüngerer Zeit finden sich Studien zur Anfälligkeit verschiedener Religionsgemeinschaften für rechtsextreme Überzeugungen (Arzheimer und Carter 2009, S. 26-27). Tragend war dabei oft die Frage, 
ob nicht das Christentum aufgrund bestimmter Normen und Überzeugungen gegen die Verbreitung rechtsextremer Haltungen immun sei. Die Ergebnisse hierfür waren, zumindest mit Blick auf rechtes Wahlverhalten, im Ländervergleich inkonsistent. In einem Land (z. B. Frankreich) bestärkte die Kirchenmitgliedschaft die Wahl rechter Parteien, in anderen (z.B. Schweiz) wirkte sie ihr entgegen. Ähnlich ambivalent fallen neuere Ergebnisse zur Messung von Effekten der Kirchenzugehörigkeit auf rechtsextreme Einstellungen aus (Pickel 2018; Rebenstorf 2018). An diesen Ergebnissen wird erkennbar: Der Blick auf die Beziehung zwischen Rechtsextremismus und Religiosität muss über die reine Zugehörigkeit zu einer Religionsgemeinschaft hinaus auf Formen der Religiosität erweitert werden. Dies ist plausibel, weil mittlerweile die religiöse Pluralisierung innerhalb der Religionsgemeinschaften zugenommen hat (Liedhegener 2018; Pickel et al. 2016). ${ }^{4}$ Es ist aber mit Blick auf Einstellungen auch überzeugend, weil dort Weltanschauungen wie auch Vorurteile ihre Differenzierung finden können.

Gerade an der Bestimmung von Vorurteilen und daraus resultierenden Aufteilungen in ,wir und die anderen“ unter religiösen Menschen kann die Analyse anschließen. Zwar ordnete Theodor Adorno in den 1950ern Religion für die von ihm untersuchte autoritäre Persönlichkeit als nur mäßig bedeutsam ein: „Religion ist im Denken der meisten Menschen nicht mehr die entscheidende Kraft wie einst; nur selten scheint sie noch soziale Anschauungen und Verhaltensweisen zu bestimmen“ (Adorno 1973, S. 280). Dennoch konnte er nicht umhin, ihr eine Rolle als Instrument für Gruppenbildungen und der Auslebung autoritärer Aggression zuzugestehen. Für Adorno (1973, S. 287) stellte sich Religion dabei mehr als Mittel der Zielerreichung denn als Selbstzweck für die Genese von Vorurteilen dar. „Ethnozentriker halten Religion oft für eine praktische Hilfe zur seelischen Hygiene" (Adorno 1973, S. 288). Also nicht die Religiosität wurde als Triebkraft gesehen, sondern die emotionale und in der Persönlichkeit sich konstituierende Abneigung gegen bestimmte Menschengruppen. Bei Adorno bezieht sich dies speziell auf das Ressentiment gegenüber Jüd:innen, also den Antisemitismus. Gerade diesen sieht er als zentralen Anlaufpunkt für Projektionen eigener Unzulänglichkeit. These 1: Antisemitische Ressentiments prägen und bestärken rechtsextreme Einstellungen.

Religiöse Elemente sind somit nicht vollständig außen vor: Zum einen dient die Zugehörigkeit zu einer ,anderen“ Religionsgemeinschaft der Kategorisierung und als Ziel von Vorurteilen, zum anderen identifiziert Adorno eine „Verlagerung von Motiven, Wünschen und Effekten in die Außenwelt" - die Projektivität (Decker et al. 2020, S. 187-188). Bei ihr kommen, neben einem Hang zur Verschwörungsmentalität, gerade Esoterik und Aberglaube als Förderer eines autoritären Charakters in den Blick. Dieser autoritäre Charakter ist dann eine zentrale Triebkraft für ethnozentristische, antipluralistische, demokratie- und fremdenfeindliche rechtsextreme Einstellungen, aber vor allem für antisemitische Ressentiments. Adorno (2020 [1951]) formulierte diese Ansicht bereits Anfang der 1950er-Jahre in seinen neun „Thesen gegen den Okkultismus“ in den „Minima Moralia“. Sie steht im Zusammenhang mit

\footnotetext{
${ }^{4}$ So unterscheiden gleich mehrere Studien, wenn überhaupt in der religiösen Differenziertheit erhoben, eher dogmatisch, konservativ denkende Christ:innen und fundamentalistisch orientierte Christ:innen von eher pluralistisch-liberal ausgerichteten Christ:innen.
} 
seinen frühen Annahmen, die „,superstition“ mit Ethnozentrismus in Einklang sahen und vor allem einer gemeinschaftlichen, sozialen Religiosität gegenüberstellten (zusammenfassend Huber und Yendell 2019, S. 68; Adorno 1973, S. 287-300). Daraus ergibt sich unsere zweite These: Esoterik und Aberglauben befördern rechtsextreme Einstellungen.

Adorno betont ebenfalls eine gewisse Ambivalenz der Wirkung christlicher Religiosität (Adorno 1973, S. 280-284). Während die Idee der christlichen Humanitas eine gewisse Immunisierung gegenüber Vorurteilen und damit rechtsextremen Haltungen verspricht, führt Instrumentalisierung und Überidentifikation mit der Eigengruppe zu Problemen. Huber und Yendell (2019, S. 68) machen ausgehend von diesen Überlegungen drei Typen aus: (1) Christ:innen, die sich mit der religiösen Gemeinschaft identifizieren, weil sie ihnen einen besseren sozialen Status und persönliche Sicherheit verspricht - sie neigen zu Ethnozentrismus; (2) intrinsisch religiöse Christ:innen, die über ihre Religion reflektieren und nicht anfällig für Ethnozentrismus sind und (3) abergläubische Menschen mit Hang zum Ethnozentrismus (und damit auch rechtsextremen Einstellungen). Das würde auch bedeuten, dass Anhänger:innen einer dogmatischen, exklusivistisch verstandenen Religiosität (d.h. Menschen, die glauben, nur ihre Religion sei „wahr") eher rechtsextrem eingestellt sein könnten als andere. Hier könnte die Neigung, andere (andersgläubige Menschen, aber auch z.B. Homosexuelle oder Transgender) abzuwerten, schon in den religiösen Lehren begründet sein. Diese konzeptionelle Brücke wird z. B. bei der neuen religiösen Rechten in den USA ausgemacht (Liensch 1982, S. 407-410; Haynes 2021, S. 6).

An dieser Stelle schließen die Studien von Gordon Allport (1950) an. Er betont die mittlerweile in verschiedenen sozialpsychologischen Gruppentheorien bedeutsame Differenz zwischen In-Group und Out-Group sowie die Bedeutung, die Vorurteile in dieser Gruppendifferenzierung besitzen. Er sieht, dass „Religion bears no univocal relationship to prejudice. Its influence is important, but it works in contradictionary directions" (Allport 1979, S. 455). Die entscheidende Differenz ist erneut die Unterscheidung einer funktionalen Nutzung für die Sicherheit und das Kontrollbewusstsein des Individuums, wodurch Ethnozentrismus und Vorurteile befördert werden, und eine christliche Überzeugung, die Toleranz fördert. „,Some people seize upon the tribal investments of traditional religion for comfort and security; others take its universalistic teaching as authentic guide to conduct" (Allport 1979, S. 455). Vor allem die Selbsterkenntnis der Sünde hilft bei der Feststellung eigener Defizite und reduziert damit die Zuweisung von Defiziten und Kategorisierungen, was eine Abwertung anderer sozialer Gruppen mit sich bringt. In einer Zusammenfassung weiterer Literatur kommen Scheepers et al. (2002, S. 246) zu einer ähnlichen Position: „This implies that those for whom their religiosity is salient (...) may be expected to live by the commandment of ,love thy neighbor" and consequently to be less prejudiced“. Folgt man diesen Überlegungen, dann kommt man zu These 3: Die Wirkung von religiöser Zugehörigkeit auf rechtsextreme Einstellungen ist ambi- 
valent. Erst das Verständnis der eigenen Religiosität entscheidet über eine Nähe oder Ferne zu rechtsextremen Einstellungen. ${ }^{5}$

Gruppenabgrenzungen zwischen religiösen Gruppen spielen dabei eine Rolle. Greift man das sowohl bei Adorno als auch bei Allport auffindbare Argument der Funktionalität von Religion als Abgrenzungsmerkmal auf, dann kann man auf klassische Ansätze der Sozialpsychologie wie Gruppenbedrohungstheorien (Group Threat Theories; Blumer 1958) oder die Social Identity Theory zurückgreifen (Tajfel 1982; Tajfel und Turner 1986). Die Social Identity Theory geht davon aus, dass die subjektive, ,gefühlte“ Zugehörigkeit zu sozialen Gruppen für das eigene Selbstwertgefühl bedeutsam sei. Sie sieht die Entscheidung eines Individuums, einer Gruppe beizutreten und sich ihr zugehörig zu fühlen, als Akt der Sicherung der eigenen Identität und der Steigerung des eigenen Selbstwertgefühls an. Für die Steigerung des Selbstwertgefühls ist demnach eine gute oder erhöhte Position der Gruppe in der Gesellschaft Voraussetzung. Diese Position kann sie durch (gemeinsame) Leistung oder aber durch die Abwertung anderer Gruppen und die damit verbundene relationale Erhöhung der eigenen Gruppe erreichen. Dazu benötigt wird eine imaginäre (Fremd-)Gruppenkonstruktion, die eine Adresse von Kategorisierung und damit oft verbunden von Abwertung ist. Die zugeschriebenen (abwertenden) Vorurteile werden von den Gruppenmitgliedern der In-Group verinnerlicht - und Gruppenmitglieder, die dieser gemeinsamen Bewertung widersprechen, sanktioniert. Dabei werden die Mitglieder der Referenzgruppe zum Ziel der Zuweisung von Stereotypen, Kategorisierungen und Abwertungen. Entsprechende Kategorisierungen können die abgelehnte Referenzgruppe als gefährlich erscheinen lassen, was die Ablehnung nur verstärkt und verschärft. Hier schließt die Integrated Threat Theory an die Social Identity Theory an: Sie postuliert eine Steigerung gruppenbezogener Vorurteile unter Bedrohungszuschreibungen (Stephan und Renfro 2002, 2016, S. 203-204; Stephan et al. 2000). Zudem unterscheidet sie symbolische und realistische Bedrohungen. Während symbolische Bedrohungen häufig auf kulturelle Ablehnungen fokussieren, greifen realistische Bedrohungen konkrete Ereignisse und Bezüge auf. Verschiedene neuere Arbeiten zeigen dabei, dass die Ablehnung von Muslim:innen beide Bedrohungsarten aufnimmt, aber im Kern vor allem eine Reaktion auf die Wahrnehmung und Zuschreibung einer symbolischen Bedrohung der eigenen Kultur bedeutet (Yendell und Pickel 2019; Pickel und Yendell 2021; Pickel et al. 2020b). Gerade als kulturell fremd wahrgenommene Gruppen und Minderheiten eignen sich besonders gut für dementsprechende Zuschreibungen. So kommen speziell Religionsgemeinschaften und ihre Mitglieder in den Blick (Uenal 2016; Pickel et al. 2020c). Sie eignen sich besonders gut aufgrund ihrer zugeschriebenen kulturellen und identitären Fremdheit für Ablehnungsprozesse. Unsere Vermutung ist, dass auf diese Weise entstehende gruppenbezogene Vorurteile, Ängste und Bedrohungswahrnehmungen gegenüber Jüd:innen und Muslim:innen zur Herausbildung rechtsextremer Einstellungen beitragen können - auch, weil insbesondere muslimfeindliche Haltungen

\footnotetext{
5 Weiterführende Studien von Allport konzentrierten sich auf extrinsische und intrinsische Religiosität als Faktor. Allerdings erbrachte die Differenzierung nur begrenzt hilfreiche Ergebnisse, abgesehen davon, dass sich eine insgesamt hochreligiöse Gruppe mit dogmatischen Haltungen als besonders offen für Vorurteile hervortat (Allport und Ross 1967, S. 440-442; Huber und Yendell 2019, S. 69).
} 
rechtspopulistischen und rechtsextremen Akteur:innen häufig zur Ansprache und Mobilisierung potenzieller Anhänger:innen dienen. These 4: Wird eine Religionsgemeinschaft als bedrohlich angesehen, verstärkt dies gruppenbezogene Vorurteile und Ressentiments, die wiederum den Weg zu rechtsextremen Einstellungen ebnen. Gleiches gilt für ein fundamentalistisches Religionsverständnis.

Eine Alternative ist die „Theorie der Gruppenbedrohung“. Diese Deprivationstheorie führt fremdenfeindliche Vorurteile auf die Zuwanderung von Minderheiten bei gleichzeitig schlechten wirtschaftlichen Verhältnissen zurück (Blumer 1958; Blalock 1967; Quillian 1995). Xenophobe Einstellungsmuster sind dementsprechend eine Reaktion der dominanten Gruppe auf eine wahrgenommene Bedrohung ihrer Gruppenposition durch eine untergeordnete Minderheit. Je größer die Bedrohung angesehen wird, umso wahrscheinlicher wird die Minderheit abgewertet (Quillian 1995, S. 588). Die Wahrnehmung der Bedrohung hängt von der Größe der Minderheitengruppe im Verhältnis zur Größe der Mehrheitsgruppe und der aktuellen wirtschaftlichen Lage ab. Eine ungünstige Wirtschaftslage fördert Bedrohungsgefühle und die Suche nach ,Sündenböcken“, die für die ökonomische Misere verantwortlich gemacht werden können. ${ }^{6}$ Beyer und Schnabel (2019. S. 8) adaptierten vor Kurzem den Theorieansatz auch für Betrachtungen zu Wechselwirkungen zwischen Religion und Politik. Dabei kamen sie zum Schluss, dass Gruppendifferenzierungen und ein „Wir versus die Anderen“ neben politischen durchaus auf religiösen Weltanschauungen beruhen kann. So gibt der Kampf zwischen dem „Guten“ und dem „Bösen“ genauso einen guten ideologischen Grund für in sozialpsychologische Modelle integrierbare Prozesse wie die eine gegenüber Kontexten abschottbare exklusive Wahrheitsannahme der eigenen Religion. „Religious narratives have the advantage to legitimate and secure their construction of meaning by attributing sacral character to social institutions and roles“ (Beyer und Schnabel 2019, S. 7; auch Johnson et al. 2011). Auf eine solche Wirkung einer religiös-zentrierten Weltanschauung verweisen auch Lenski (1963) und Scheepers et al. (2002, S. 245). Dies führt zu These 5: Besitzen religiöse Menschen eine exklusivistische Haltung, dass die eigene Religion die einzig richtige sei, dann sind sie offener für Gruppenabgrenzungen, Vorurteile und letztendlich rechtsextreme Einstellungen.

Die wenigen aktuelleren Studien zu Ethnozentrismus und Vorurteilen zeigen immer wieder Bezüge zwischen Vorurteilen und rechtsextremen Einstellungen sowie empirische Wechselwirkungen von Vorurteilen mit Religiosität oder Formen der Religiosität (Billiet 1995; Billiet et al. 1995; Fulton et al. 1999; Huber und Yendell 2020; Johnson et al. 2011; Lienesch 1982; Middelton 1973; Moghaddam und Vuksanovic 1990; Pickel et al. 2020b; Roof 1974; Strabac und Listhaug 2007). Die Ergebnisse legen nahe, dass gruppenbezogene Vorurteile und Ressentiments zu Brücken für eine Annäherung zwischen Religion und rechtsextremen Einstellungen

\footnotetext{
6 Trotz aller Kritik an der Theorie der Gruppenbedrohung (Triandafyllidou 1998; Pettigrew 1998; Sigelman und Welch 1993) trägt sie doch immer wieder inhaltlich zur Erklärung der Abwertung von Minderheiten bei (Hjerm 2007).

7 Speziell scheinen es Haltungen gegenüber nicht-binärer heterosexueller Orientierung und Antifeminismus zu sein (Höcker et al. 2020), die zu Annäherungen von eher konservativen bis dogmatischen Gläubigen in Richtung rechtsextremer Einstellungen führen.
} 
werden können. ${ }^{7}$ Das sichtbarste Verbindungsmerkmal ist der Antisemitismus, ist er doch sogar ein charakterisierendes Element einer rechtsextremen Einstellung, wie es auch Fremdenfeindlichkeit ist. Hinsichtlich letzterer hat man in den letzten Jahren den Eindruck gewinnen müssen, dass vor allem die Abgrenzung gegenüber Muslim:innen und „dem Islam“ zu einem tragenden Kennzeichen rechtsextremer und rechtsradikaler Einstellungen geworden ist (Marzouki et al. 2016; Yendell 2014). Zumindest konzentrieren sich rechte Kampagnen in der Öffentlichkeit verstärkt auf dieses Feindbild. Entsprechend erweist sich die Ablehnung des Islam als wichtiges Mobilisierungsmerkmal für die Wahl rechtspopulistischer Parteien (u.a. Pickel 2019b; Pickel und Pickel 2018b; Rippl und Seipel 2018). Es ist davon auszugehen, dass die Ausrichtung auf andere Religionsgemeinschaften verbunden mit dem Narrativ der „Verteidigung des Abendlandes“ gut mit einem völkisch-nationalen Rechtsextremismus harmoniert: These 6: Neben antisemitischen Ressentiments fungieren gerade Vorurteile gegenüber Muslim:innen als Brücke zu rechtsextremen Einstellungen.

Neben dem Grundkonzept der Nächstenliebe und des christlichen Universalismus kann man noch einen weiteren Ansatz für die Annahme, dass christliche Religiosität als Sozialform rechtsextremen Einstellungen entgegenwirkt, heranziehen. Diese Annahme basiert auf der Kontakthypothese, wonach Kontakte zu Mitgliedern der OutGroup zum Abbau von Vorurteilen beitragen (Allport 1979; Pettigrew 1998; Pettigrew und Tropp 2006). Kontakte zu Mitgliedern anderer Religionsgemeinschaften sollten daher vorurteilsreduzierend wirken - und damit mittelfristig auch rechtsextremen, völkischen Einstellungen Unterstützung entziehen. Dieser Zusammenhang konnte zuletzt empirisch für Kontakte zu Muslim:innen in mehreren ost- und westeuropäischen Ländern nachgewiesen werden (Pickel und Öztürk 2018, 2020 auch Pollack et al. 2014; Pickel und Yendell 2016). Wir vermuten daher, dass christliche Religiosität zum einen durch in der christlichen Lehre verankerte Wertvorstellungen, zum anderen durch mit religiösem Engagement verbundene Gelegenheitsstrukturen für Kontakte dazu beitragen kann, möglicherweise bestehende Bedrohungswahrnehmungen, Ängste oder Vorurteile gegenüber Jüd:innen und Muslim:innen abzubauen. These 7: Kontakte mit Mitgliedern anderer Religionsgemeinschaften reduzieren Vorurteile ihnen gegenüber und mindern auf diesem Weg die Verbreitung von rechtsextremen Einstellungen.

\section{Die Messung rechtsextremer Einstellungen und ihre Probleme}

Um die Beziehungen zwischen Religion und rechtsextremen Einstellungen in den Blick nehmen zu können, ist es notwendig, das Phänomen rechtsextremer Einstellungen und die Möglichkeit ihrer Messung zu bestimmen. Wie lassen sich rechtsextreme Einstellungen messen? Wie kann man solche Haltungen treffend operationalisieren und dabei Antworten im Sinne sozialer Erwünschtheit oder auch Differenzen in den Verständnissen von Befragten soweit wie möglich reduzieren? Um der Verwirrung von Rezipient:innen durch unterschiedliche Messkonstrukte zu rechtsextremen Einstellungen zu begegnen, entwickelten mehrere Forscher:innen (die „Konsensusgruppe“) 2001 eine Konsensdefinition rechtsextremer Einstellungen, die aus sechs 
Unterdimensionen besteht (Kiess et al. 2015; Decker et al. 2013b, S. 198-199). Von zentraler Bedeutung ist hier mit Rückgriff auf das bereits präsentierte Verständnis von Rechtsextremismus die Ideologie der Ungleichheit und Ungleichwertigkeit, die mit einer Akzeptanz von Gewaltanwendung und dem Sturz des demokratischen politischen Systems einhergeht. Rechtsextremismus steht im Gegensatz zur Demokratie. Sein Ziel ist letztlich, einen Systemumsturz herbeizuführen und ein autoritäres System zu etablieren. Die Ideologie der Ungleichwertigkeit zeigt sich bei rechtsextremen Einstellungen sowohl im politischen als auch im sozialen Bereich:

Der Rechtsextremismus ist ein Einstellungsmuster, dessen verbindendes Kennzeichen Ungleichwertigkeitsvorstellungen darstellen. Diese äußern sich im politischen Bereich in der Affinität zu diktatorischen Regierungsformen, chauvinistischen Einstellungen und einer Verharmlosung bzw. Rechtfertigung des Nationalsozialismus. Im sozialen Bereich sind sie gekennzeichnet durch antisemitische, fremdenfeindliche und sozialdarwinistische Einstellungen. (Decker und Brähler 2006, S. 20)

Damit wird allerdings auch deutlich, dass rechtsextreme Einstellungen ein Phänomen sind, das verschiedene Aspekte miteinander verbindet. Wissenschaftstheoretisch gesprochen handelt es sich um eine latente Dimension, die über die Erhebung der Unterdimensionen abgebildet werden kann. Nach der Konsensdefinition beinhalten rechtsextreme Einstellungen folgende Dimensionen:

1. Affinität zu Diktatur als Staatsform

2. Nationaler Chauvinismus

3. Verharmlosung des Nationalsozialismus

4. Antisemitismus

5. Fremdenfeindlichkeit

6. Sozialdarwinismus

Diese Dimensionen werden im Rahmen von Umfragen in Statements umgesetzt. Sie dienen als Reize, die auf indirektem Weg versuchen, die Positionierung der Befragten zu einem Phänomen herauszuarbeiten (Pickel und Pickel 2018a, S. 182-191). In den Leipziger Autoritarismus-Studien (vormals Leipziger ,Mitte“-Studien) werden diese sechs Dimensionen seit 2002 mit jeweils drei Items und fünf Antwortmöglichkeiten ( $1=$ lehne völlig $a b, 2=$ lehne überwiegend $a b, 3=$ stimme teils zu, teils nicht $\mathrm{zu}, 4=$ stimme überwiegend $\mathrm{zu}, 5=$ stimme voll und ganz $\mathrm{zu}$ ) gemessen (Decker et al. 2013b, S. 199-202, 2020, S. 34-37). Für diesen Artikel von besonderem Interesse sind die Dimensionen Antisemitismus und Fremdenfeindlichkeit, da sich hierin ablehnende Einstellungen gegenüber Jüd:innen und Muslim:innen (und somit gegenüber als anders bzw. fremd wahrgenommenen religiösen Gruppen) zeigen. Dies impliziert ein statistisches Problem: So sind teilweise die zu erklärenden Konstrukte - Muslimfeindlichkeit und Antisemitismus auf der Einstellungsebene in den rechtsextremen Einstellungen mit involviert. Dem versuchen wir durch die Konstruktion von Teilskalen etwas entgegenzuarbeiten. Auf der theoretischen Ebene bedeutet dies allerdings auch, dass rechtsextreme Einstellungen mit der Ablehnung anderer Religionsgemeinschaften und deren Mitglieder bereits konzeptionell verzahnt sind. 
Für die folgenden Darstellungen und Analysen werden aufgrund der unterschiedlichen Verfügbarkeit von uns interessierenden Erklärungsfaktoren verschiedene Umfragedaten herangezogen: Analytisch werden Daten der Allgemeinen Bevölkerungsumfrage der Sozialwissenschaften (ALLBUS) 2018 unter Einbezug von Fragen des International Social Survey Programmes (ISSP) 2018 zu Religion und der Survey des Forschungsprojekts „Konfigurationen individueller und kollektiver religiöser Identitäten und ihre zivilgesellschaftlichen Potenziale (KONID)“ 2019 die Grundlage des Beitrages darstellen. Ergänzend greifen wir auf - teilweise veröffentlichtes Datenmaterial der Leipziger Autoritarismus-Studien (2002-2020), des Bertelsmann Religionsmonitors 2013 und 2017 sowie des ALLBUS 2016 zurück (genauere Informationen $\mathrm{zu}$ den einzelnen Studien sind im Anhang aufgeführt). Als weiteres Problem für die vorliegende Fragestellung erweist sich dabei, dass es nur wenige Daten gibt, die sowohl rechtsextreme Einstellungen als auch Religiosität differenziert erfassen (z. B. über die bloße Zugehörigkeit zu einer Religionsgruppe hinaus). Das hat zur Folge, dass vollständige Analysen (bislang) zwischen beiden Aspekten nicht herzustellen sind. In den von uns ausgewählten Datensätzen kommen zumindest eine breitere Messung von Religiosität und mehrere (leider nicht alle) Dimensionen rechtsextremer Einstellungen zusammen (welche genau, ist ebenfalls im Anhang ersichtlich). Wir denken aber, dass trotzdem mit dem vorliegenden Datenmaterial inhaltliche Schlüsse auf die Beziehungen zwischen Religiosität und rechtsextremen Einstellungen möglich sind.

Zur Abbildung der Religiosität und zur Prüfung der Thesen wurden in der KONID-Studie erfreulicherweise neben klassischen Indikatoren der Religionsmessung (These 3) Aussagen zum religiösen Exklusivismus und einem sozialen bzw. liberalen Verständnis sowie Kontakte zu Mitgliedern anderer Religionsgemeinschaften erhoben (These 5 und These 7). Auch eine Erhebung von Bedrohungswahrnehmungen sowie von antisemitischen Ressentiments und auch Muslimfeindlichkeit liegt in diesem Datensatz vor (These 1, These 4 und These 6). In der ALLBUSStudie wiederum konnte der Einfluss der Esoterik über den Glauben an Wahrsager:innen (These 2) ermittelt werden. Genaue Itembeschreibungen finden sich im Anhang.

\section{Entwicklung und Verbreitung rechtsextremer Einstellungen in Deutschland seit 2002}

Zur Veranschaulichung der Präsenz rechtsextremer Einstellungen nutzen wir eine Abbildung aus der jüngsten Veröffentlichung der Leipziger Autoritarismus-Studie (Decker et al. 2020, S. 51; Abb. 1). Sie stellt den Anteil der Befragten mit geschlossen rechtsextremem Weltbild im Zeitverlauf dar. Als „geschlossen rechtsextrem“ Eingestellte gelten Befragte, die im Durchschnitt allen sechs Dimensionen rechtsextremer Einstellungen zustimmen. Um den Anteil der Befragten mit geschlossen rechtsextremem Weltbild zu ermitteln, verwenden die Autor:innen einen Indexwert, der diejenigen Befragten als Anhänger:innen eines solchen Weltbildes definiert, die in ihren Antworten über alle Dimensionen hinweg einen Wert von mehr als 63 (von insgesamt maximal 90 Punkten) aufweisen (Decker et al. 2020: 50). Darunter fallen 


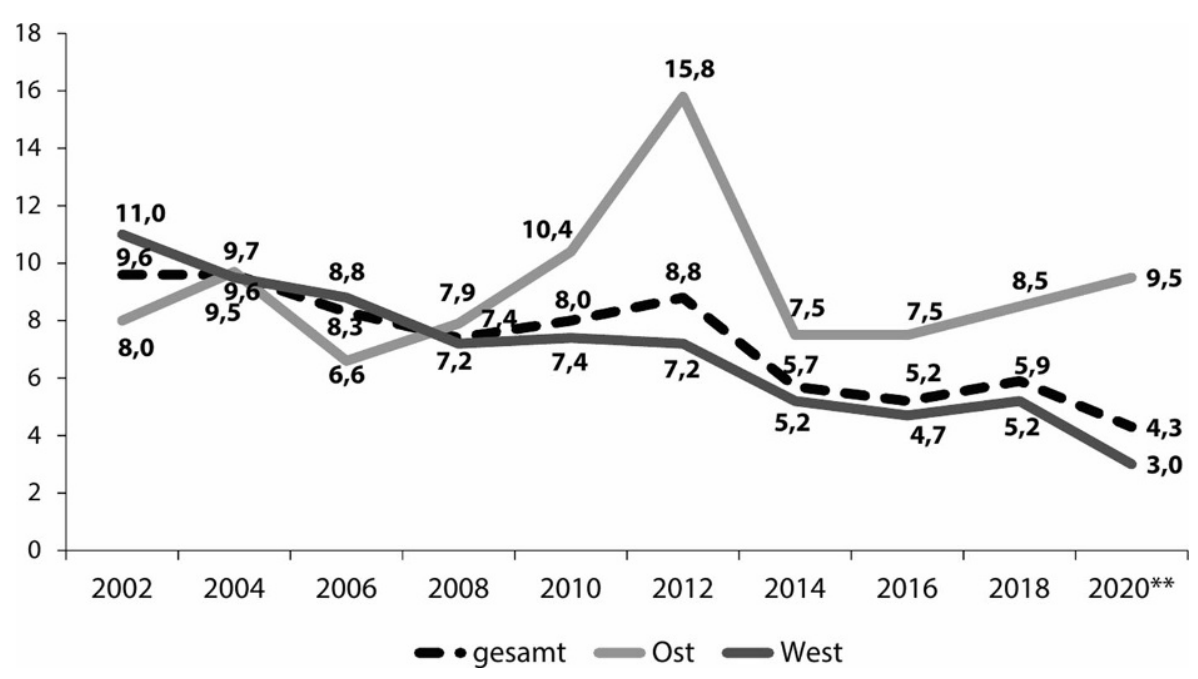

Abb. 1 Anteil der Befragten mit geschlossen rechtsextremem Weltbild 2002-2020 (in \%). Quelle: Leipziger „Mitte“-Studien/Leipziger Autoritarismus-Studien 2002-2020 (Decker et al. 2020, S. 51); = 2500 Befragte

Befragte, die bei den Einzelaussagen durchschnittlich auf einen Wert von mindestens 3,5 kommen. Das bedeutet, dass sie im Durchschnitt allen 18 Items manifest zustimmen.

Der Anteil an Deutschen mit einem geschlossen rechtsextremen Weltbild liegt seit einigen Jahren bei ca. fünf Prozent (Abb. 1). Dieser Anteil ist für Gesamtdeutschland sowie für Westdeutschland seit 2002 leicht rückläufig und zwischen 2018 und 2020 nochmals merklich gesunken. Für Ostdeutschland gilt diese Beobachtung hingegen nicht: Hier ist der Anteil der Befragten mit geschlossen rechtsextremem Weltbild seit 2006 und insbesondere nach der Finanzkrise 2008 angestiegen. Nach einem Absinken 2014 nimmt die Verbreitung rechtsextremer Einstellungen in Ostdeutschland seit 2016 wieder kontinuierlich zu. Insgesamt teilen heute mehr Ostdeutsche ein geschlossen rechtsextremes Weltbild als zu Beginn der Messungen 2002 - und seit 2008 mehr als in Westdeutschland. ${ }^{8}$

Offen bleibt die Interpretation des Ergebnisses: So kann man den Wert von fünf Prozent als geringe Verbreitung eines geschlossenen rechtsextremen Weltbildes in Deutschland auslegen. Gleichzeitig ist die Existenz von fast zehn Prozent überzeugter Rechtsextremer in Ostdeutschland doch Grund zur Sorge - vor allem, wenn man sich vor Augen führt, dass die Zustimmungsraten zu bestimmten Unterdimensionen des Rechtsextremismus durchaus deutlich höher ausfallen können. In Abb. 2

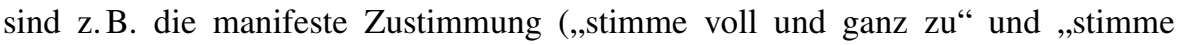

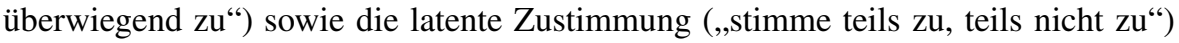
zu den Aussagen der Dimensionen „Ausländerfeindlichkeit“" sowie „Chauvinismus“

\footnotetext{
8 Die Unterschiede sind signifikant: Pearsons Chi-Quadrat: **p $<0,01$, signifikanter Unterschied zwischen Ost und West in 2020.
} 


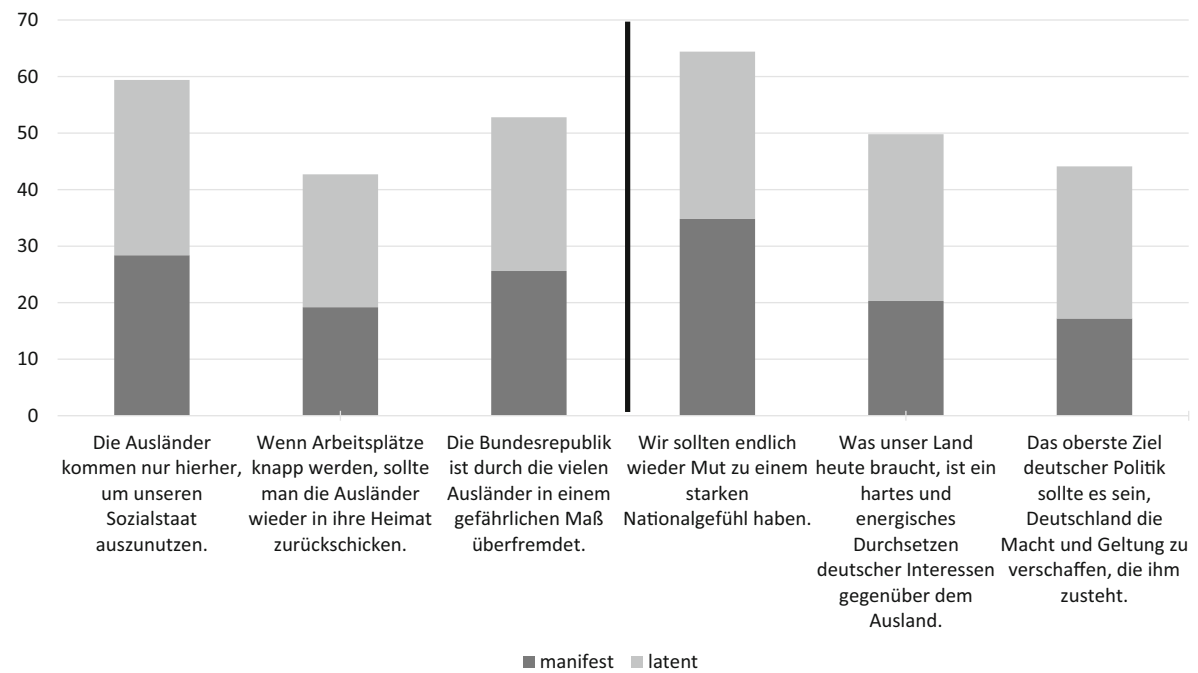

Abb. 2 Manifeste und latente Zustimmung zu den Aussagen der Dimensionen „Ausländerfeindlichkeit“ (links) und „Chauvinismus“ (rechts, in \%). Quelle: Eigene Darstellung auf Grundlage der Leipziger Autoritarismus-Studie 2020

dargestellt. ${ }^{9}$ Das Diagramm zeigt, dass fremdenfeindliche und chauvinistische Ansichten in der Bevölkerung weit verbreitet sind: So findet sich knapp $30 \%$ manifeste Zustimmung zu den Aussagen „Die Ausländer kommen nur hierher, um unseren Sozialstaat auszunutzen“ und „Die Bundesrepublik ist durch die vielen Ausländer in einem gefährlichen Maß überfremdet“. Der dritten fremdenfeindlichen Aussage stimmen knapp $20 \%$ manifest zu. Hinzu kommen bei allen drei Aussagen zwischen etwa 20 und $30 \%$ latente Zustimmung. Was Chauvinismus anbelangt, stimmen sogar über $30 \%$ der Aussage ,Wir sollten endlich wieder Mut zu einem starken Nationalgefühl haben“" zu - und noch einmal so viele lehnen sie nicht explizit ab. Die beiden anderen chauvinistischen Aussagen werden zwar weniger stark vertreten (ca. $20 \%$ manifeste Zustimmung), aber zusammen mit der latenten Zustimmung von jeweils ca. $30 \%$ sind auch diese Werte als hoch anzusehen.

Die Zustimmung zu den anderen Dimensionen rechtsextremer Einstellungen (Befürwortung einer rechtsautoritären Diktatur, Sozialdarwinismus, Verharmlosung des Nationalsozialismus und Antisemitismus) fällt im Vergleich deutlich niedriger aus (hier nicht in Diagrammen dargestellt). Folglich finden sich bei der Messung rechtsextremer Einstellungen sogenannte „harte“ und „weiche“ Items der Messung. Zu den eher harten Items zählen die Dimensionen Sozialdarwinismus und Verharmlosung des Nationalsozialismus. Beim Sozialdarwinismus findet die Aussage „Eigentlich sind die Deutschen anderen Völkern von Natur aus überlegen“" mit etwas über $10 \%$

\footnotetext{
9 Bei der Verwendung der Mittelkategorie als latente Dimension handelt es sich um eine durchaus kontrovers diskutierte Besonderheit der Leipziger Autoritarismus Studien. Die Idee ist, dass die nicht explizite Ablehnung unter Berücksichtigung eines starken Drucks sozialer Erwünschtheit der Ablehnung eben eine latente Zustimmung ausdrückt.
} 
noch die höchste manifeste Zustimmung (bei knapp $20 \%$ latenter Zustimmung). Bei NS-Verharmlosung ist es die Aussage „Ohne Judenvernichtung würde man Hitler heute als großen Staatsmann ansehen“ mit knapp 10\% manifester Zustimmung (bei gut $15 \%$ latenter Zustimmung). Auch hier könnte man die Werte als niedrig einstufen. Das Problem ist, dass beide Aussagen ein undemokratisches und menschenverachtendes Einstellungsgebäude zeichnen, das möglichst gar nicht existieren und auf grundsätzliche Ablehnung stoßen sollte. Hier erzeugt die Vorstellung, dass ein Viertel der Deutschen solche Aussagen nicht ablehnt, ein ungutes Gefühl.

Auch primärer Antisemitismus scheint mit maximal etwa zehn Prozent manifester Zustimmung zu den einzelnen Items auf den ersten Blick eher selten zu sein (bei jeweils zwischen etwa 20 und 25\% latenter Zustimmung). Dennoch ist ein Anteil von $10 \%$ der Befragten, die der Aussage ,Auch heute noch ist der Einfluss der Juden zu groß“ zustimmen, vor dem Hintergrund der deutschen Erinnerungskultur beachtlich hoch. So sollte eigentlich bei Fragen zum (primären) Antisemitismus das Antwortverhalten der Befragten aufgrund der historischen Schuld Deutschlands im Sinne sozialer Erwünschtheit sehr gering ausfallen. Im Gegenteil, es sollte eigentlich eine einhellige Ablehnung bestehen. Dies ist zwar mehrheitlich, aber nicht bei allen deutschen Staatsbürger:innen der Fall, wie die $25 \%$ Nichtablehnung zeigen.

In der Leipziger Autoritarismus-Studie wird daher neben dem primären Antisemitismus auch sekundärer Antisemitismus gemessen (vgl. Kiess et al. 2020). Dieser ist in der Bevölkerung weiter verbreitet als der primäre Antisemitismus. Man spricht hier von einer „Umwegkommunikation“, die die doch beachtlichen Bestände antisemitischer Ressentiments teilweise aus dem Blick von Betrachter:innen hält (Kiess et al. 2020, S. 221-223; Decker et al. 2018, S. 187-190). Vor allem zeigt sich dieser sekundäre Antisemitismus in einem deutlichen Schuldabwehrantisemitismus: So stimmen z. B. über $40 \%$ der Deutschen einer Aussage wie „Reparationsforderungen an Deutschland nutzen oft gar nicht den Opfern, sondern einer Holocaust-Industrie von findigen Anwälten“ zu (Kiess et al. 2020, S. 226). Vergleichbare Items ergeben ähnliche Zustimmungsraten. Ergänzt wird der sekundäre Antisemitismus neuerdings noch durch einen israelbezogenen Antisemitismus. Beide ergänzenden Formen antisemitischer Einstellungen finden allerdings keinen Eingang in die Rechtsextremismusskala.

Zusammenfassend lässt sich feststellen, dass 2020 der Anteil der Befragten mit geschlossen rechtsextremem Weltbild mit 4,3\% in Gesamtdeutschland (bzw. $3 \%$ in Westdeutschland und 9,5\% in Ostdeutschland) eher niedrig liegt, die Zustimmung zu einzelnen Dimensionen rechtsextremer Einstellungen jedoch teils wesentlich höher ausfällt. Zudem findet sich eine breitere Latenz in Form einer nicht expliziten Ablehnung von Dimensionen des Rechtsextremismus, die Anschlussfähigkeiten für rechte Akteur:innen eröffnet. Hierin könnten Rechtspopulist:innen bzw. Rechtsextreme ein Mobilisierungspotenzial sehen, indem sie an weit verbreitete ablehnende Einstellungen gegenüber Ausländer:innen (und häufig auch spezifische Bedrohungswahrnehmungen gegenüber ,,dem Islam“ bzw. Muslim:innen) anknüpfen - eine Strategie, die sich ab 2014/2015 z. B. bei der rechtspopulistischen, muslim- und fremdenfeindlichen PEGIDA ${ }^{10}$ in Dresden und ihren Ableger-Organisationen in anderen

10 Akronym für „Patriotische Europäer gegen die Islamisierung des Abendlandes“. 
Städten beobachten ließ. Mit Blick auf Religion lässt sich feststellen, dass Religion als Ablehnungsmarker implizit in rechtsextremen Einstellungen enthalten ist (z.B. Antisemitismus), aber nur begrenzt überzeugte antisemitische Einstellungen (mit Blick auf den primären Antisemitismus) geäußert werden. Doch auch hier bestehen weit reichende Latenzen und Umwegkommunikationen, die Juden und Jüdinnen ethnisieren und als Feindbild markieren.

\section{5 Ängste und Vorurteile gegenüber anderen Religionen und rechtsextreme Einstellungen}

Bevor wir zur Messung der Beziehungen zwischen Religiosität, Vorurteilen und rechtsextremen Einstellungen kommen, werfen wir noch einen Blick auf die Haltung der deutschen Bürger:innen zum Islam und zu Muslim:innen. Wie soeben gesehen, finden wir einen geringen primären Antisemitismus, aber einen doch beachtlichen sekundären und israelbezogenen Antisemitismus. Wie sieht es nun für Muslim- oder Islamfeindlichkeit (siehe Diekmann 2017) aus? Ablehnende Haltungen gegenüber Muslim:innen und ,dem Islam“ sind spätestens seit dem 11. September 2001 in der deutschen Bevölkerung verbreitet und haben mit den Fluchtbewegungen nach Europa 2015 verstärkt an Visibilität gewonnen (Pickel 2019b; Haynes 2021, S. 14). Die Spannbreite der Abwehr und gruppenbezogenen Vorurteile ist beachtlich (Abb. 3). So sind es zwar Minderheiten, die eine Einreise von Muslim:innen unterbinden wollen, aber es finden sich starke soziale Distanzen und Vorurteile im Alltagsleben. ${ }^{11}$ Immerhin mehr als ein Viertel der Deutschen bekundet eine zumindest eher negative Einstellung gegenüber Muslim:innen, und noch häufiger wird eine Beschränkung der muslimischen Glaubenspraxis gefordert - ganz im Kontrast zum Grundrecht der Religionsfreiheit und dem Grundgesetz. Letzteres gilt auch für die 2016 recht weit verbreitete Forderung, islamische Gemeinschaften zu beobachten. Vermutlich denken hier viele Befragte an aus ihrer Sicht islamistische Glaubensgemeinschaften.

Die Daten des Religionsmonitors zeigen die nach Stellung im Radius des persönlichen Nahbereichs zunehmende soziale Distanz. Unter allen dort abgefragten Religionsgemeinschaften war die soziale Distanz gegenüber Muslim:innen am höchsten (Pickel 2019a, S. 78). Berücksichtigt man den Radius von einem unangenehmen Gefühl (,Fühle mich fremd im Land aufgrund der vielen Muslime“) bis hin zur (harten) Ablehnung spezifisch muslimischer Zuwanderung, dann entfaltet sich das Bild eine beachtlichen sozialen Distanz gegenüber Muslim:innen in fast der Hälfte der Bevölkerung, die bei ca. einem Fünftel bis Viertel der Deutschen zu einer Muslimfeind-

\footnotetext{
11 Unterschiede im Antwortverhalten, wie sie hier mit Bezug auf die Ablehnung muslimischer Zuwanderung zu erkennen sind, beruhen oft auf Unterschieden in den Erhebungsmethoden. So wird z. B. die Leipziger Autoritarismus Studie, anders als der Religionsmonitor oder die KONID-Studie, nicht als Telefonbefragung, sondern als Selbstausfüllerfragebogen mit Interviewerbetreuung durchgeführt. Dementsprechend sind manche der erhobenen Werte vermutlich sogar zu positiv, und man kann sie als konservative Einschätzung verstehen.
} 
Durch die vielen Muslime hier fühle ich mich manchmal wie ein Fremder im eigenen Land (LAS 2020)

Man sollte Islamische Gemeinschaften beobachten (Allbus 2016)

Einheirat von Muslim in Familie wäre unangenehm (Religionsmonitor 2017)

Befürworte Einschränkungen muslimischer Glaubenspraktiken (Allbus 2016)

Einstellung zu Muslimen negativ + eher negativ (Allbus 2018)

Muslimen sollte Zuwanderung nach Deutschland untersagt werden (LAS 2020)

Muslimen sollte Zuwanderung nach Deutschland untersagt werden (KONID 2019)

Muslimen sollte Zuwanderung nach Deutschland untersagt werden (Religionsmonitor 2017)

Hätte Muslime nicht gerne als Nachbarn

(Religionsmonitor 2017)

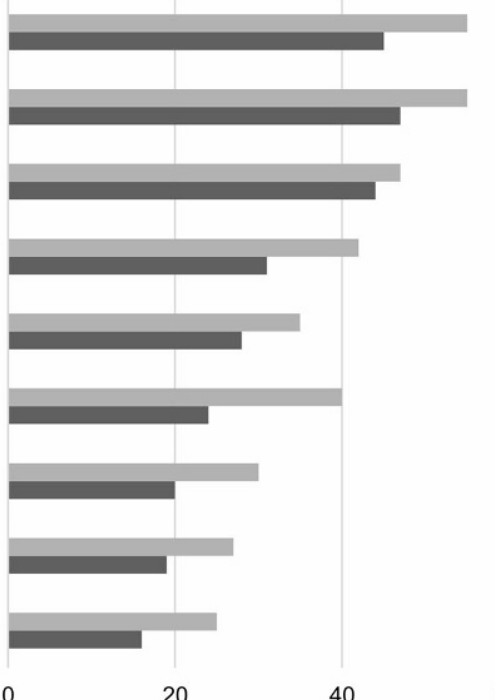

0

20

40

Ostdeutschland $\quad$ Westdeutschland

Abb. 3 Zustimmung zu muslimfeindlichen Aussagen (in \%). Quelle: Eigene Berechnungen, unterschiedliche Datenquellen; Allgemeine Bevölkerungsumfrage der Sozialwissenschaften (ALLBUS) 2016, 2018; Konfigurationen individueller und kollektiver religiöser Identitäten und ihre zivilgesellschaftlichen Potenziale (KONID) 2019; Leipziger Autoritarismus Studie (LAS) 2020 (Decker et al. 2020, S. 65); Religionsmonitor 2017 (Pickel 2019a, S. 78-79)

lichkeit führt (z. B. ausgedrückt in nicht konditionierter Zuwanderungsablehnung). ${ }^{12}$ Entsprechen diese Ergebnisse den Überlegungen der Social Identity Theory und weiteren vorliegenden empirischen Analysen (u.a. Pickel 2019b; Pickel und Öztürk 2019; Öztürk und Pickel 2020, 2021; Strabac und Listhaug 2007), so stellt sich doch auch die Frage, warum soziale Distanzen und ablehnende Einstellungen bei teilweise über der Hälfte der Bundesbürger:innen festzustellen sind. Eine Erklärung hierfür ist mit dem 11. September 2001 verbunden. So haben die damaligen Geschehnisse das Bild vom Islam und übertragen von Muslim:innen stark negativ geprägt. Hier kann die oben bereits erwähnte Integrated Threat Theory als Erklärung herangezogen werden. So ist es eben die Assoziation des Islam mit Gewalt, Gefahr, kultureller Fremdheit und Unmodernität, die eine oft diffuse Ablehnungshaltung mit sich bringt. Dies stützen Daten des Bertelsmann Religionsmonitors von 2013 und 2017 (Abb. 4).

\footnotetext{
12 Nicht nur die Zuwanderungsfrage kennzeichnet die Sicht auf Muslim:innen in Deutschland, aber auch anderen Ländern als von der Zuschreibung kultureller Fremdheit und einem „Othering“ getragen. Dementsprechend kann man gerade bei der harten Ablehnung Elemente eines antimuslimischen Rassismus ausmachen (Shooman 2014). Hinzu kommt - spätestens seit 2015 - eine enge Verzahnung des Bildes von Geflüchteten und Muslim:innen (Pickel und Pickel 2019). Dabei werden Migrant:innen oder Geflüchtete, die als muslimisch identifiziert werden, ethnisiert und politisiert. Muslimfeindlichkeit trifft daher nicht zwangsläufig ausschließlich Muslim:innen, sondern kann darüber hinaus auch Migrant:innen nichtmuslimischen Glaubens sowie säkulare Muslim:innen treffen (Spielhaus 2018, S. 140). Gleichwohl bleibt die Markierung der „Feinde“ über eine zugewiesene Zugehörigkeit zu einer Religionsgemeinschaft.
} 


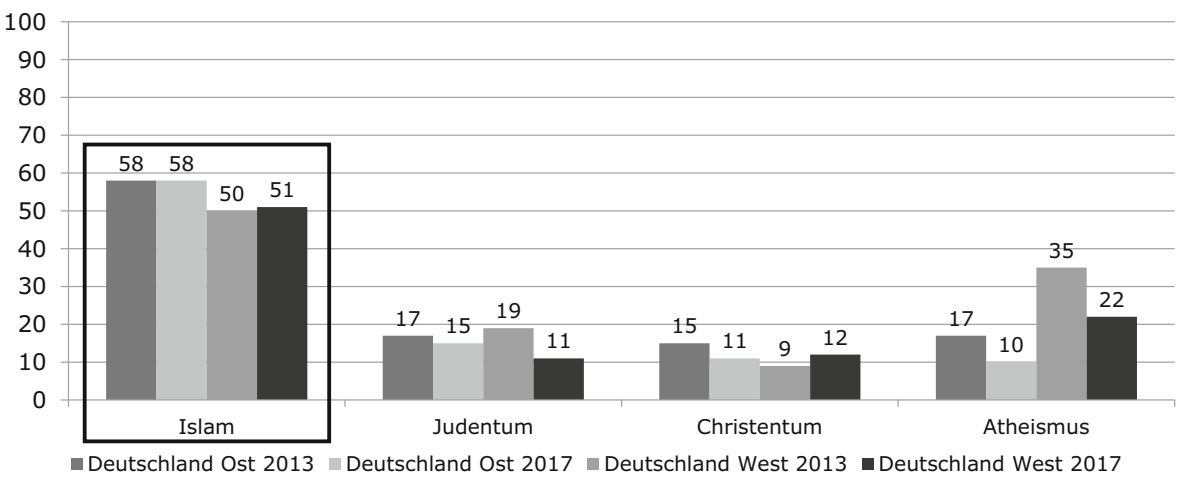

Abb. 4 Bedrohungswahrnehmungen gegenüber verschiedenen Religionen. Quelle: Bertelsmann Religionsmonitor 2013 und 2017: Wenn Sie an die Religionen denken, die es auf der Welt gibt: Als wie bedrohlich bzw. wie bereichernd nehmen Sie die folgenden Religionen wahr? Anteil sehr bedrohlich/eher bedrohlich (Pickel 2019a, S. 80)

Der Islam wird unter den abgefragten Religionen als mit Abstand am bedrohlichsten wahrgenommen: Mindestens 50\% der Befragten schätzten ihn 2013 wie 2017 als sehr oder eher bedrohlich ein. Dabei dürfte die mediale Berichterstattung über ISIS und die Allgegenwärtigkeit des rechten Narrativs einer Überfremdung bis hin zur gesteuerten „Umvolkung“ diese Einschätzungen bestärkt haben. Bedrohungswahrnehmungen gegenüber dem Judentum sowie dem Christentum fallen im Vergleich deutlich geringer aus: Zwischen 9 und 19\% halten diese beiden Religionen für sehr oder eher bedrohlich. Dabei ist auch die beachtliche Bedrohungswahrnehmung des Judentums vor dem Hintergrund des sehr geringen jüdischen Bevölkerungsanteils bemerkenswert. Hier werden vermutlich die „Strippenzieher“ für die „Umvolkung“ gesehen. Lässt man einmal andere interessante Unterschiede beiseite, fällt bei näherem Hinsehen auf, dass das Bedrohungsgefühl wie auch schon die soziale Distanz und Muslimfeindlichkeit (Abb. 3) in Ostdeutschland immer etwas stärker ausfällt als in Westdeutschland. Gleichzeitig liegt der Anteil der Muslim:innen in Ostdeutschland erheblich niedriger als im Bundesschnitt $(<1,0 \%)$. Erklären lässt sich diese größere Sorge z.B. mit der oben dargelegten Kontakthypothese, wonach Kontakte, am besten unfreiwillige Kontakte, die soziale Distanz und Ablehnung anderer sozialer Gruppen reduzieren. Dies findet in Westdeutschland statt, in Ostdeutschland eher selten. Hier greifen stärker parasoziale Kontakte, also die Wahrnehmung von Muslim:innen und „dem Islam“ im Fernsehen oder über vergleichbare Medien. Diese fällt mit Bezug auf die genannten Ereignisse eher ungünstig aus und befördert eine gewisse Abwehrhaltung vor dem als gefährlich wahrgenommenen Islam (Pickel und Yendell 2006; Pollack et al. 2014).

Es hat sich also gezeigt, dass Religionsgemeinschaften und deren Mitglieder Ziel von gruppenbezogenen Vorurteilen, Abwertung, Ungleichwertigkeitsvorstellungen und sozialer Distanz sind. Dies gilt sowohl für das Judentum als auch für den Islam. In welchem Verhältnis stehen diese Vorurteile nun aber zu rechtsextremen Einstellungen? Für antisemitische Ressentiments ist dies bereits auf der analytischen Ebene zu klären: Antisemitismus ist integraler Bestandteil eines rechtsextremen Weltbil- 
Tab. 1 Zusammenhänge zwischen Rechtsextremismus, Antisemitismus, Muslimfeindlichkeit

\begin{tabular}{lll}
\hline & Antisemitismus & Muslimfeindlichkeit \\
\hline Rechtsextremismus & $0,580^{* *}$ & $0,440^{* *}$ \\
& $0,489^{* *}$ & $0,294^{* *}$ \\
Antisemitismus & $0,581^{* *}$ & $0,408^{* *}$ \\
& - & $0,487 * *$ \\
& & $0,200^{* *}$ \\
\hline
\end{tabular}

Korrelation nach Pearson $\mathrm{r}$

*signifikant auf dem 0,05-Niveau, **signifikant auf dem 0,01-Niveau, n. s. nicht signifikant Quelle: Eigene Berechnungen auf Grundlage des KONID 2019, ALLBUS 2018 (unter Einbezug des ISSP 2018) und LAS 2018 (Pickel und Yendell 2018, S. 28); Berechnungen zwischen rechtsextremen Einstellungen und antisemitischen Einstellungen unter Ausschluss letzterer aus der Rechtsextremismusskala (für die begrenzte Messung in der KONID-Studie wurde zudem die Ausländerfeindlichkeit ausgeschlossen, um hier keinem Verzerrungseffekt zu unterliegen)

des und wird als eine der sechs genannten Dimensionen rechtsextremer Einstellungen erfasst (Decker und Brähler 2020). Da überrascht es dann auch nicht, dass antisemitische Ressentiments in allen unseren drei Untersuchungsdatensätzen mit rechtsextremen Einstellungen (vorher um antisemitische Ressentiments bereinigt) hochsignifikant in Beziehung stehen (Tab. 1). ${ }^{13}$

Gleiches gilt für die Muslimfeindlichkeit. Rechtsextreme Einstellungen hängen (in allen drei verwendeten Untersuchungen) signifikant mit Muslimfeindlichkeit zusammen, auch wenn man den übergreifenden Faktor Fremdenfeindlichkeit aus Gründen methodischer Sauberkeit aus der Messung rechtsextremer Einstellungen exkludiert (tut man dies nicht, erhält man einen Wert von $r=0,72$ in der KONID-Studie). Muslimfeindlichkeit bzw. Angst vor dem Islam dient Rechtsextremen - wie man es entsprechenden Kampagnen ablesen kann - als wichtiger Mobilisierungsfaktor, und zwar bis in die Mitte der Gesellschaft hinein, wie es die Beziehungen zwischen Muslimfeindlichkeit und Rechtspopulismus zeigen (Pickel 2018; Lesch 2017; Öztürk und Pickel 2019, 2021; Rebenstorf 2018). Die Ergebnisse variieren dabei ein wenig entlang der Konstruktionen der eingesetzten Rechtsextremismusskalen. Aber eindeutig ist: Muslimfeindlichkeit wie auch antisemitische Einstellungen sind einem rechtsextremen Weltbild, oder auch erst einmal rechtsextremen Teilüberzeugungen, förderlich. In gewisser Hinsicht dient die Ablehnung beider Glaubensgemeinschaften und ihrer Mitglieder als wichtige Brücke zum Rechtsextremismus. Selbst wenn vielleicht auch andere Vorurteile für eine solche Beziehung herangezogen werden könnten (Antifeminismus, Sexismus, Antizganismus), nicht in Frage stellen kann man nunmehr, dass die Abwertung von Mitgliedern anderer Religionsgemeinschaften, teilweise gesteigert durch die Wahrnehmung oder Einstufung als bedrohlich, rechtsextreme Einstellungen befördert.

\footnotetext{
13 Dabei ist anzumerken, dass die Abbildung für rechtsextreme Einstellungen nur in der LAS, nicht jedoch in der ALLBUS- bzw. KONID-Studie dem Idealmodell der Messung von Rechtsextremismus entspricht. Allerdings konnten Indikatoren für zentrale Bereiche rechtsextremer Einstellungen gefunden werden (welche genau, ist aus dem Anhang ersichtlich).
} 


\section{Rechtsextreme Einstellungen und ihre religiösen Triebkräfte}

\subsection{Verbreitung rechtsextremer Einstellungen in verschiedenen Religionsgemeinschaften}

Wie sieht es nun mit der Wirkung von Religionszugehörigkeit auf rechtsextreme Einstellungen aus? Die Daten der Leipziger Autoritarismus-Studie von 2018 zeigen - wie bereits andere Studien - eine geringe Varianz über die Angehörigen der unterschiedlichen Religionsgemeinschaften sowie über die Konfessionslosen (Abb. 5; Billiet 1995, S. 320; Pickel 2018, S. 289; Pickel und Yendell 2018, S. 222; Rebenstorf 2018, S. 324). ${ }^{14}$ Die Ausprägungen variieren nur leicht. Muslim:innen sind am wenigsten rechtsextrem eingestellt, während orthodoxe Christ:innen am ehesten rechtsextreme Haltungen teilen. Allerdings sollte man aufgrund der geringen Fallzahlen bei orthodoxen Christ:innen und Muslim:innen bei Rückschlüssen vorsichtig sein.

Ähnliche Bilder ergeben sich auch für Auswertungen der ALLBUS-Daten von 2018 oder der KONID-Studie 2019: Angehörige aller Religionsgemeinschaften wie auch Konfessionslose sind in etwa ähnlich stark rechtsextrem eingestellt. Es zeigen sich kaum tendenzielle Effekte von Religiosität an sich oder auch von der Zugehörigkeit zu einer der aufgeführten Gruppen auf rechtsextreme Haltungen. Die Mitgliedschaft oder Nicht-Mitgliedschaft in einer Religionsgemeinschaft scheint dem-

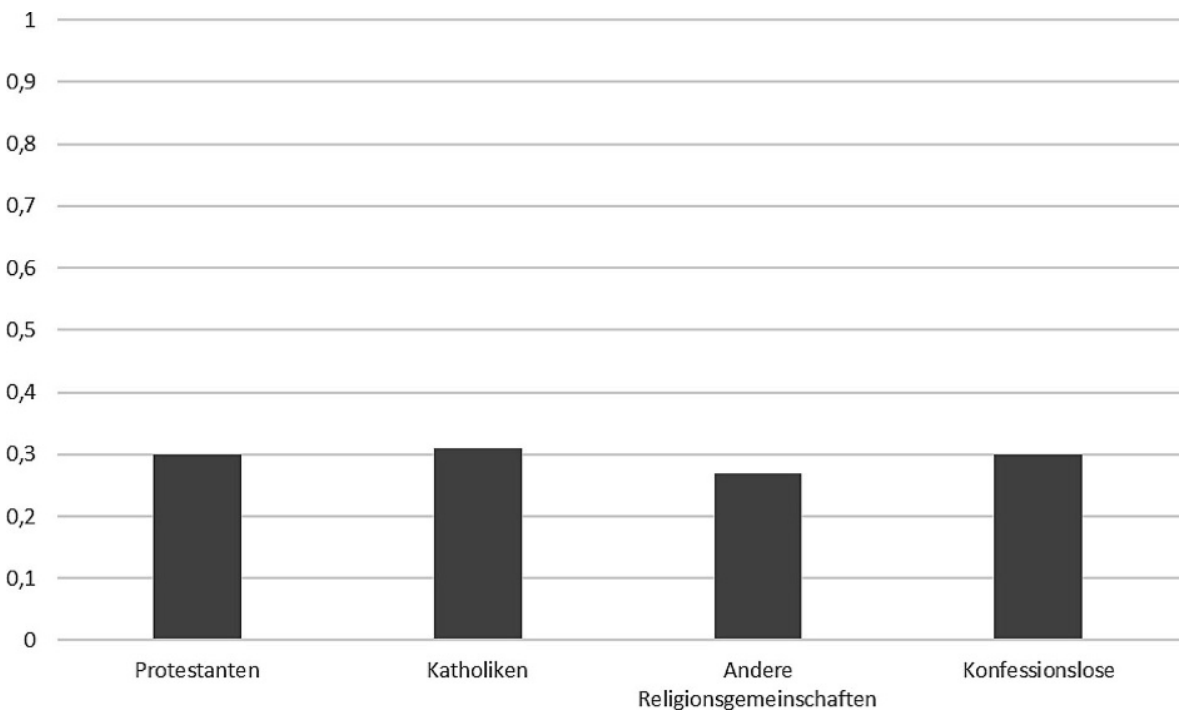

Abb. 5 Rechtsextreme Einstellungen nach Religionsgemeinschaft (LAS). Quelle: Eigene Darstellung auf Grundlage der Leipziger Autoritarismus-Studie 2018; dargestellt Mittelwerte des Rechtsextremismusindex; $n=2502$

14 Vergleichbare Studien finden gelegentlich Vorurteile bei Katholik:innen oder Protestant:innen. Doch wenn dies der Fall ist, sind die Differenzen durchweg gering (siehe Küpper und Zick 2006, 2017; Rebenstorf 2018). 
nach weder hemmende noch befördernde Effekte auf rechtsextreme Einstellungen zu besitzen - unabhängig davon, ob es sich um in Landeskirchen organisierte Protestant:innen, Protestant:innen in Freikirchen, Katholik:innen, Anhänger:innen anderer christlicher oder nicht-christlicher Religionsgemeinschaften oder um Konfessionslose handelt. ${ }^{15}$

\subsection{Erklärungsfaktoren für rechtsextreme Einstellungen}

Nun ist allerdings die gestiegene innere Pluralität von Religionsgemeinschaften genauso zu berücksichtigen wie kontextuelle Faktoren. Entsprechend betrachten wir verschiedene politische, wirtschaftliche und religiöse Erklärungsfaktoren gemeinsam in multivariaten Regressionsanalysen. So ist es uns möglich, religiöse Effekte unter Berücksichtigung alternativer Einflussfaktoren zu ermitteln, und es kann vermieden werden, dass man bestimmte Einflüsse überschätzt und hinter ihnen stehende latente Einflüsse übersieht (Pickel und Pickel 2019, S. 169-181). Wir unterscheiden in der Analyse soziale und dogmatische Religiosität: Während erstere religiöses mit sozialem Engagement verbindet und sowohl durch christliche Werte als auch durch Gelegenheitsstrukturen für zwischenmenschliche Kontakte helfen könnte, Vorurteile abzubauen, wird bei letzterer eine eher vorurteilsfördernde Wirkung angenommen. Mit der Einschätzung, der einzig ,wahren“ Religionsgemeinschaft anzugehören, könnte die Neigung zur Abwertung anderer religiöser Gruppen einhergehen. Darüber hinaus wollen wir den vermuteten Zusammenhang zwischen Esoterikglauben und gruppenbezogenen Vorurteilen bzw. rechtsextremen Einstellungen überprüfen.

Wir beginnen mit Berechnungen anhand des ALLBUS 2018 (Tab. 2). Im ersten Modell, das ausschließlich religiöse sowie soziodemografische unabhängige Variablen beinhaltet, sehen wir vor allem zwei deutliche Effekte: niedrige Bildung, die sich als Rechtsextremismus fördernd erweist, sowie ein Wohnsitz in Westdeutschland, der rechtsextreme Einstellungen hemmt. Esoterikglauben (gemessen durch den Glauben an Wahrsager:innen) hat ebenfalls einen hochsignifikanten, wenn auch schwächeren fördernden Effekt auf Rechtsextremismus. Damit scheint sich Adornos (1973) Annahme einer Wirkung der Projektivität auf Vorurteile und rechtsextreme Einstellungen bei Esoterik zu bewahrheiten (These 2). Auch scheinen Katholik:innen tendenziell rechtsextremer eingestellt zu sein als Konfessionslose, und Männer stärker als Frauen. Diese beiden Effekte sind allerdings lediglich auf dem 0,05-Niveau signifikant (im Gegensatz zum 0,01-Niveau bei den zuvor genannten Effekten). Die Selbstbeschreibung als religiös, der Glaube an einen persönlichen Gott, die öffentliche religiöse Praxis (Gottesdienstbesuch bzw. Besuch einer Moschee, einer Synagoge oder eines anderen Gotteshauses) sowie eine soziale Religiosität haben keinen signifikanten Effekt auf rechtsextreme Haltungen. Die vermutete hemmende Wirkung sozialer Religiosität auf rechtsextreme Einstellungen lässt sich anhand der ALLBUS-Daten nicht bestätigen. Ebenfalls keine signifikanten Effekte zeigen sich für die Konfessionszugehörigkeiten ,evangelisch“ und ,,andere“ (mit Konfes-

\footnotetext{
15 Was angesichts einer beobachteten etwas stärkeren Präsenz bestimmter Vorurteile unter Mitgliedern der Freikirchen durchaus bemerkenswert ist (Pickel et al. 2020c, S. 173).
} 
Tab. 2 Regressionsanalyse auf rechtextreme Einstellungen (ALLBUS)

\begin{tabular}{lll}
\hline & Modell 1 & Modell 2 \\
\hline Selbstbeschreibung als religiös & n.s. & n.s. \\
Glaube an einen persönlichen Gott & n.s. & n.s. \\
Öffentliche religiöse Praxis & n.s. & n.s. \\
Soziale Religiosität & n.s. & n.s. \\
Esoterik & $0,084^{* *}$ & $0,073^{* *}$ \\
Konfession: evangelisch (Ref: Konfessionslose) & n.s. & n.s. \\
Konfession: katholisch (Ref: Konfessionslose) & $0,071^{*}$ & n.s. \\
Konfession: andere (Ref: Konfessionslose) & n.s. & n.s. \\
Rechts auf der Links-Rechts-Skala & $(-)$ & $0,312^{* *}$ \\
Gefühl fehlender politischer Wirkung & $(-)$ & $0,101^{* *}$ \\
Wirtschaftliche Lage wird als gut bewertet & $(-)$ & $-0,055^{*}$ \\
Eigene wirtschaftliche Lage wird als gut bewertet & $(-)$ & $-0,064^{* *}$ \\
Soziales Vertrauen & $(-)$ & $-0,199^{* *}$ \\
Wohnsitz in Westdeutschland (Ref.: Ostdeutschland) & $-0,111^{* *}$ & $-0,106^{* *}$ \\
Niedrige Bildung (Ref.: Hohe Abschlüsse) & $0,314^{* *}$ & $0,179^{* *}$ \\
Geschlecht (Ref.: weiblich) & $0,057^{*}$ & n.s. \\
Alter & n.s. & n.s. \\
Korrigiertes R & 0,125 & 0,305 \\
\hline
\end{tabular}

Lineare Regression, Beta-Koeffizienten

*signifikant auf dem 0,05-Niveau, **signifikant auf dem 0,01-Niveau, n. s. nicht signifikant, mit (-) ausgewiesen, wenn Variablen nicht ins Modell integriert wurden

Quelle: Eigene Berechnungen auf Grundlage des ALLBUS 2018 (unter Einbezug von Items des ISSP 2018)

sionslosen als Referenzkategorie). Dies entspricht allerdings der Annahme einer ambivalenten Wirkung.

Im zweiten Modell, das auch alternative (z.B. politische und wirtschaftliche) Erklärungsfaktoren berücksichtigt, sehen wir fünf relativ starke signifikante Effekte: Die eigene politische Verortung als rechts auf einer Links-Rechts-Skala, das Gefühl fehlender politischer Selbstwirkung (political efficacy) sowie eine niedrige formale Bildung wirken sich fördernd auf rechtsextreme Einstellungen aus, während soziales Vertrauen sowie ein Wohnsitz in Westdeutschland rechtsextreme Überzeugungen hemmen. Die Einschätzung der nationalen wirtschaftlichen Lage als gut wirkt Rechtsextremismus ebenfalls entgegen (signifikant auf dem 0,05-Niveau) - ein Effekt, der sich in ähnlicher Weise und sogar noch deutlicher für die Bewertung der persönlichen wirtschaftlichen Lage als gut zeigen lässt (signifikant auf dem 0,01-Niveau). Bei den untersuchten möglichen religiösen Einflussfaktoren (Selbstbeschreibung als religiös, Glaube an einen persönlichen Gott, öffentliche religiöse Praxis und soziale Religiosität) zeigen sich keine signifikanten Effekte. Ebenfalls keine Effekte gehen in diesem Modell von der Konfessionszugehörigkeit als evangelisch, katholisch oder andere (im Verhältnis zu Konfessionslosen) aus. Der Effekt des Esoterikglaubens bleibt jedoch auch in diesem Modell sehr signifikant. Esoterikglauben scheint also im Sinne Adornos (1973) tatsächlich mit einer Offenheit für Rechtsextremismus einherzugehen. Vermutlich ist es die Nähe zu Verschwörungsmentalität, 
Tab. 3 Regressionsanalyse auf Rechtsextremismus (KONID)

\begin{tabular}{|c|c|c|c|}
\hline & Modell 1 & Modell 2 & Modell 3 \\
\hline Selbstbeschreibung als religiös & n.s. & n.s. & $-0,078 * *$ \\
\hline Öffentliche religiöse Praxis & n.s. & n.s. & n. s. \\
\hline Konfession: evangelisch & n.s. & n.s. & n.s. \\
\hline Konfession: katholisch & n.s. & n.s. & n. s. \\
\hline Konfession: andere Religionsgemeinschaften & $n . \mathrm{s}$ & $n . \mathrm{s}$ & n.s. \\
\hline $\begin{array}{l}\text { Kontakt mit Mitgliedern anderer Religionen wird als } \\
\text { positiv wahrgenommen }\end{array}$ & $-0,215^{* *}$ & $-0,120 * *$ & $-0,055^{*}$ \\
\hline $\begin{array}{l}\text { Kombination der eigenen Religiosität mit sozialem Enga- } \\
\text { gement }\end{array}$ & $(-)$ & $(-)$ & $-0,078 * *$ \\
\hline $\begin{array}{l}\text { Dogmatisch-fundamentalistische Auslegung der eigenen } \\
\text { Religion }\end{array}$ & $(-)$ & $(-)$ & $0,323 * *$ \\
\hline Liberale Auslegung der eigenen Religion & $(-)$ & $(-)$ & $-0,065^{*}$ \\
\hline Autoritarismus-Skala & $(-)$ & $0,358 * *$ & $0,314 * *$ \\
\hline Gefühl fehlender politischer Wirkung & $(-)$ & $0,134 * *$ & $0,105^{* *}$ \\
\hline Befragte(r) sieht sich als Verlierer:in in der Gesellschaft & $(-)$ & $0,155 * *$ & $0,107 * *$ \\
\hline Befragte(r) fühlt sich depriviert & $(-)$ & $0,096^{* *}$ & $0,106^{* *}$ \\
\hline Eigene wirtschaftliche Lage wird als schlecht bewertet & $(-)$ & $0,073 * *$ & $0,057 *$ \\
\hline Rechts auf der Links-Rechts-Skala & $(-)$ & $0,220 * *$ & $0,175^{* *}$ \\
\hline Wohnsitz in Westdeutschland (Ref.: Ostdeutschland) & $-0,081 * *$ & n.s. & n. s. \\
\hline Wohnsitz in einer Großstadt (Ref.: andere Wohnorte) & $-0,068 * *$ & n.s. & $-0,056^{*}$ \\
\hline Hohe Bildung (Ref.: andere Abschlüsse) & $-0,136 * *$ & n.s. & n.s. \\
\hline Geschlecht (Ref.: weiblich) & $0,089 * * *$ & $0,078 * *$ & $0,052 *$ \\
\hline Alter & $-0,070 * *$ & $-0,047 *$ & n. s. \\
\hline Korrigiertes $\mathrm{R}^{2}$ & 0,083 & 0,403 & 0,481 \\
\hline
\end{tabular}

Lineare Regression, Beta-Koeffizienten

*signifikant auf dem 0,05-Niveau, **signifikant auf dem 0,01-Niveau, n. s. nicht signifikant

Quelle: Eigene Berechnungen auf Grundlage des KONID 2019-Survey; Referenzkategorie für Konfessionen ist Konfessionslosigkeit; mit (-) ausgewiesen, wenn Variablen nicht ins Modell integriert wurden

die für diesen Effekt verantwortlich ist (Schließler et al. 2020; S. 288-293). Geschlecht und Alter haben in diesem Modell keinen signifikanten Effekt.

Vergleichbare Analysen mit dem KONID-Survey 2019 (Tab. 3) ähneln den zuvor berichteten Befunden. Wie dem Modell 1 entnommen werden kann, hat die Religiosität von Individuen - gemessen an ihrer Selbstbeschreibung als religiöse Person, ihrer öffentlichen religiösen Praxis und konfessionellen Selbstverortung keinen Effekt auf rechtsextreme Einstellungen. Allenfalls lässt sich im Sinne der Kontakthypothese konstatieren, dass Bürger:innen, die den Kontakt mit Mitgliedern anderer Religionen als positiv erleben, für rechtsextreme Positionen weniger empfänglich sind. Rechtsextreme Einstellungsmuster sind zudem in Teilen sozialstrukturell vermittelt: In Westdeutschland, in Großstädten und unter Bürger:innen mit hohen Bildungsabschlüssen finden rechtsextreme Einstellungen weniger Rückhalt. Eine höhere Zustimmung zu rechtsextremen Einstellungsmustern findet sich zudem unter Männern und in der vergleichsweise jungen Bevölkerung. Keiner dieser Faktoren sollte jedoch in seiner Bedeutung überschätzt werden, so kann das Modell 1 gerade einmal 8,3\% der Varianz der abhängigen Variable erklären. Wie Modell 2 
zeigt, sind andere Einflussfaktoren entscheidend. Besonders hervorzuheben ist ein klarer Effekt des Autoritarismus auf rechtsextreme Überzeugungen. Hier bestätigen sich verschiedene Befunde der Autoritarismusforschung (Decker und Brähler 2018, 2020). Hinzu kommen politische, gesellschaftliche und wirtschaftliche Deprivationsbzw. Marginalisierungserfahrungen, wie sie für die group threat theory grundlegend sind. Wenn Bürger:innen zu der Einschätzung gelangen, dass ihre Stimme keinen Einfluss auf das Regierungshandeln hat und dass sie eher zu den „Verlierer:innen“ der Gesellschaft gehören ${ }^{16}$, weil sie viel weniger bekommen als ihnen zustehen würde, weisen sie eine stärkere Empfänglichkeit für den Rechtsextremismus auf. In die gleiche Richtung wirkt eine negative Beurteilung der eigenen wirtschaftlichen Lage. Alles in allem überwiegen somit nicht-religiöse Triebfaktoren bei der Formation von rechtsextremen Einstellungsmustern.

Nichtdestotrotz lohnt sich eine Binnendifferenzierung in der Gruppe der religiösen Bürger:innen, die in ihrer Gesamtheit weder empfänglicher noch immuner für rechtsextreme Einstellungen ist. Eine solche Binnendifferenzierung findet sich in Modell 3, weil die Fragen nach der Auslegung der eigenen Religion - ob nun dogmatisch-fundamentalistisch oder eher liberal - sowie dem eigenen sozialen Engagement im religiösen Umfeld nur den ,religiös-musikalischen Befragten“ vorgelegt wurden. Den Ergebnissen ist zu entnehmen, dass sich die gesellschaftlichen Polarisierungstendenzen auch innerhalb der religiösen Gemeinden in Deutschland wiederfinden. Besonders hervorzuheben ist hierbei, dass sich eine dogmatisch-fundamentalistische Auslegung der eigenen Religion als ausgesprochen starker Triebfaktor rechtsextremer Einstellungen erweist. Der Effekt ist beachtlich und übertrifft - in der Gruppe der gläubigen Individuen - sogar den Effekt von autoritären Überzeugungen. Sicherlich, die Zahl fundamentalistisch denkender Christ:innen ist begrenzt (knapp 10\% in der evangelischen und katholischen Kirche, allerdings $40 \%$ in der begrenzten Gruppe der Mitglieder der Freikirchen; Pickel et al. 2020c, S. 175), gleichwohl zeigt dieser Zusammenhang ein markantes und mit Überlegungen von Allport (1979) harmonierendes Anfälligkeitsmuster. Rechtsextreme Einstellungen hemmend hingegen wirkt es, wenn Befragte die eigene Religiosität mit sozialem Engagement verbinden. ${ }^{17}$ Gläubige, die ihre Religion als soziale Religion verstehen und liberal auslegen, können rechtsextremem Denken nichts abgewinnen. Diese Gruppe ist deutlich größer und umspannt um die $40 \%$ der Kirchenmitglieder. Damit scheinen unsere Thesen 3 und 5 stichhaltig zu sein und auch die ihnen vorausgehenden Theorien zu bestätigen.

Diese Ergebnisse korrespondieren mit Vergleichsberechnungen zu gruppenbezogenen Vorurteilen (Pickel et al. 2020c, S. 184-185). So sind die dogmatischen Christ:innen offener für Vorurteile, die eher eine soziale Religiosität aufweisenden Christ:innen ablehnender gegenüber Vorurteilen und offener für Pluralismus. Angesichts der beachtlichen Zahl an Kontrollvariablen im Modell 3 ist dies ein

\footnotetext{
16 Entsprechende Items zu Autoritarismus, Fundamentalismus und zum Gefühl, ein(e) Verlierer:in zu sein, waren im ALLBUS nicht enthalten, sodass hier kein Vergleich möglich ist.

17 Dieses Ergebnis unterscheidet sich von dem der ALLBUS-Analyse, wo kein signifikanter Effekt von sozialer Religiosität festgestellt wurde. Dies dürfte auf die ungünstige Operationalisierung dort zurückzuführen sein.
} 
hochgradig belastbares Ergebnis. ${ }^{18}$ Eine fundamentalistische, dogmatische Haltung sowie Esoterikglauben (oder Aberglauben nach Adorno 1973) stützen rechtsextreme Überzeugungen.

\subsection{Die ambivalente Wirkung von Religiosität auf rechtsextreme Einstellungen}

Religiosität scheint somit in zwei Richtungen zu wirken. Zusätzlich zu den Regressionsmodellen haben wir ein bewusst verknapptes Mediationsmodell berechnet (Hayes 2017; Abb. 6). Mit diesem statistischen Verfahren überprüfen wir, ob zwischen der Selbstbeschreibung als religiöse Person und rechtsextremen Einstellungen indirekte Beziehungen vorliegen. Hierbei modellieren wir zwei Pfade - eine dogmatisch-fundamentalistische Auslegung der eigenen Religion und eine Kombination der eigenen Religiosität mit sozialem Engagement in religiösen Gemeinden. Zusätzlich zu den beiden Pfaden bzw. Mediatoren kontrollieren wir die Bildung sowie das Geschlecht und das Alter der Befragten.

Wie in Modell 1 und 2 der zuvor präsentierten Regressionen lässt sich kein direkter, statistisch signifikanter Effekt der Selbstbeschreibung als religiöse Person auf rechtsextreme Einstellungen feststellen. Es wäre jedoch vorschnell, hieraus zu schließen, dass keine Beziehung zwischen „Religion“ und „Rechtsextremismus“ vorliegt. Die Selbstbeschreibung als religiöse Person wirkt als eine Hintergrundvariable, die mit dogmatisch-fundamentalistischen Auslegungen der eigenen Religion (Regressionskoeffizient von 0,276; signifikant auf dem 0,01-Niveau), aber auch mit

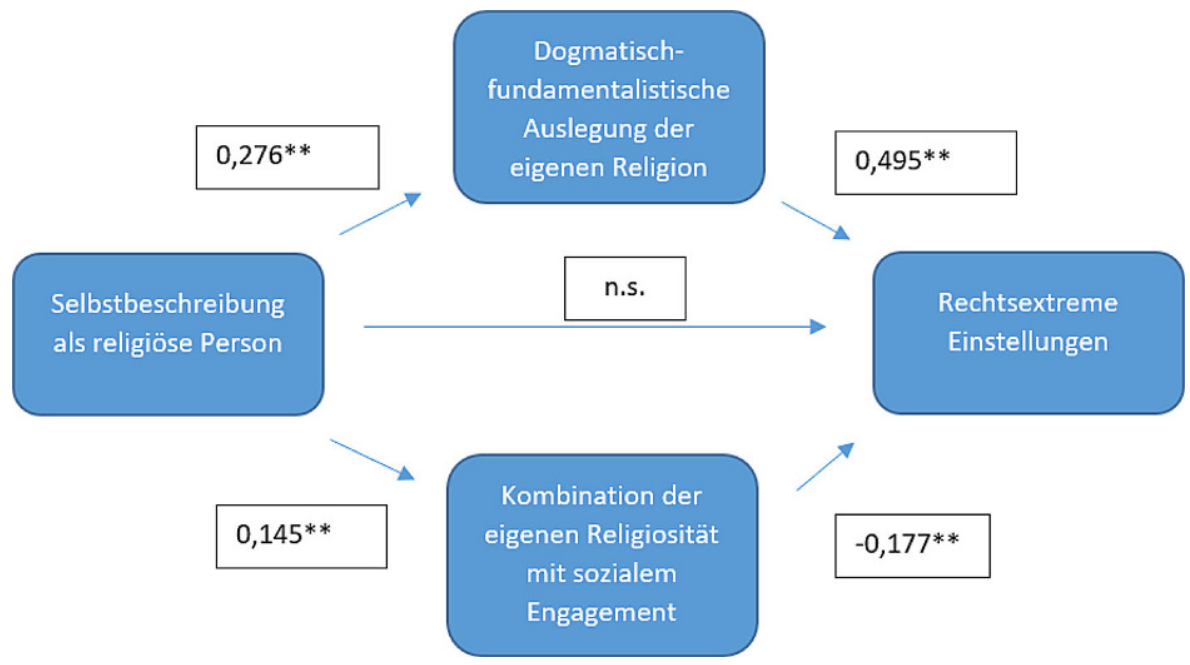

Abb. 6 Mediationsmodell zum Zusammenhang von Religiosität und Rechtsextremismus. **signifikant auf dem auf dem 0,01-Niveau, n.s. nicht signifikant. Quelle: Eigene Berechnung auf Grundlage des KONID-Survey 2019. Anmerkung: Das Mediationsmodell wurde auf Grundlage von Andrew F. Hayes (2017) PROCESS Makro für SPSS berechnet. Hierbei wurde das Modell 4 verwendet

18 Huber und Yendell (2019, S. 73-76) kommen in einer Studie zur Bedeutung von Religion für die Wahl der AfD ebenfalls zu hemmenden Effekten des Kirchgangs, speziell in einem säkularen Gebiet wie Ostdeutschland, und zu die Wahl fördernden Effekten von Aberglauben und Esoterik. 
sozialem Engagement in religiösen Gemeinden (Regressionskoeffizient 0,145; signifikant auf dem 0,01-Niveau) im Verhältnis steht. Während Personen, die ihre eigene Religion dogmatisch-fundamentalistisch auslegen, eine größere Empfänglichkeit für rechtsextreme Einstellungen aufweisen, verhält es sich unter den besonders aktiven Mitgliedern religiöser Gemeinden andersherum: Je höher ihr soziales Engagement in der Gemeinde ist, desto immuner sind die Befragten gegenüber rechtsextremen Weltbildern - oder eigentlich sogar widerständiger. Denn unter den sozial engagierten Christ:innen finden sich anscheinend überdurchschnittlich viele, die dem Rechtsextremismus entgegentreten. Dementsprechend kann die Beziehung zwischen Religiosität und rechtsextremen Überzeugungen als ambivalent beschrieben werden: Sie hängt maßgeblich davon ab, wie Individuen ihre eigene Religion auslegen und welche individuellen Motivationen sie aus ihrer Religiosität ableiten. Folge davon ist allerdings auch, dass gerade sehr überzeugte religiöse Menschen unterschiedliche Haltungen zu einer zentralen politischen Frage in einer Demokratie aufweisen. Dabei sind die Kräfteverhältnisse zudem ungleich, übersteigt doch die Zahl der sozial engagierten religiösen Menschen die der dogmatischen bis fundamentalistischen Christ:innen deutlich. Liberale Auslegungen der eigenen Religion sind in Deutschland nämlich - über die Konfessionen hinweg - der Regelfall (siehe Pickel et al. 2020c). Klar erkennbar wird: Allein religiös oder Christ:in zu sein, schützt keineswegs vor rechtsextremen Einstellungen. Im Gegenteil, bei einem bestimmten Glaubensverständnis sind Vorurteile, Abgrenzung bis hin zu rechtsextremen Vorstellungen gut vereinbar mit dem Glauben. Zumeist allerdings wirkt der christliche Glauben entgegengesetzt als Hemmfaktor für rechtsextreme Einstellungen und damit einer Offenheit für Rechtsextremismus.

Dabei entsteht eine Nähe dogmatischer oder exklusivistisch denkender Christ:innen zum Rechtsextremismus vermutlich seltener im Zuge einer vollständigen Identifikation mit Rechtsextremist:innen. Vielmehr ist anzunehmen, dass gruppenbezogene Vorurteile als Brückenköpfe für Wahlverwandtschaften mit Rechtsextremist:innen dienen. Aufgrund der beachtlichen Korrelationen zwischen Vorurteilen und rechtsextremen Einstellungen haben wir auf deren Einbezug in die Regressionsanalysen verzichtet. Werfen wir also zum Abschluss unserer Analysen noch einen kurzen Blick auf die Zusammenhänge zwischen gruppenbezogenen Vorurteilen, Rechtsextremismus und dogmatisch-fundamentalistischer Religion (Tab. 4). Wie zu erwarten, hängen verschiedene gruppenbezogene Vorurteile und Ressentiments in erheblichem Umfang mit rechtsextremen Überzeugungen zusammen. Etwas geringere, aber noch immer klare empirische Effekte zeigen sich zwischen rechtsextremen Einstellungen einerseits und Homophobie sowie der Ablehnung von Gleichstellungspolitik andererseits. Die Ergebnisse von hier nicht ausgewiesenen Berechnungen mit den ALLBUS-Daten entsprechen diesen Resultaten, wenn man berücksichtigt, dass nicht zu allen im KONID abgefragten sozialen Gruppen bzw. zu Fundamentalismus auch im ALLBUS vergleichbare Items enthalten waren.

Gruppenbezogene Vorurteile sind die Brücke und der Einstieg in rechtsextreme Überzeugungen. Dementsprechend nutzen auch rechtsextreme und rechtsradikale Parteien bestehende soziale Distanzen und Vorurteile in der Bevölkerung zu ihren Gunsten und versuchen, sie zu bestärken. Wie sieht es nun mit der religiösen Seite aus? Es finden sich direkte Zusammenhänge mit der subjektiven Religiosität. Sie 
Tab. 4 Bezüge zwischen Dimensionen rechtsextremer Einstellungen, verschiedenen Vorurteilen

\begin{tabular}{llll}
\hline & $\begin{array}{l}\text { Rechtsextreme } \\
\text { Einstellungen }\end{array}$ & $\begin{array}{l}\text { Dogmatische } \\
\text { Religiosität }\end{array}$ & Religiosität \\
\hline Ausländerfeindlichkeit & $0,538^{* *}$ & $0,216^{* *}$ & n.s. \\
Muslimfeindlichkeit & $0,624^{* *}$ & $0,306^{* *}$ & n.s. \\
Flüchtlingsfeindlichkeit & $0,603^{* *}$ & $0,240^{* *}$ & n.s. \\
Antiziganismus & $0,581^{* *}$ & $0,250^{* *}$ & $-0,045^{*}$ \\
Primärer Antisemitismus & $0,554^{* *}$ & $0,281^{* *}$ & n.s. \\
Israelbezogener Antisemitismus & $0,390^{* *}$ & $0,200^{* *}$ & $-0,068^{* *}$ \\
Homophobie & $0,488^{* *}$ & $0,377^{* *}$ & $0,163^{* *}$ \\
Ablehnung von Gleichstellungspolitik & $0,405^{* *}$ & $0,178^{* *}$ & $0,067^{* *}$ \\
\hline
\end{tabular}

Korrelation nach Pearson $r$

*signifikant auf dem 0,05-Niveau, **signifikant auf dem 0,01-Niveau, n. s. nicht signifikant Quelle: Eigene Berechnungen auf Grundlage des KONID 2019.

sind aber, wenn sie bestehen, in der Regel schwach, oder, wie im Falle von Antiziganismus und dem israelbezogenen Antisemitismus, sogar entgegengesetzt. Am stärksten ist der Zusammenhang mit Homophobie (auch Fulton et al. 1999, S. 18; Pickel et al. 2020c, S. 184). Ähnliches wäre für andere Indikatoren zum Antifeminismus und Sexismus zu erwarten, die aber in der KONID-2019-Studie nicht abgefragt wurden. Allgemein kann man von der hohen Religiosität eines Individuums nicht auf Vorurteilsstrukturen schließen (Altemeyer und Hunsberger 1992, S. 124-126; Billiet 1995, S. 319-321), womit weder die generelle Annahme einer schützenden Funktion des Glaubens bestätigt wird noch die Verweise auf eine grundsätzliche Problemhaftigkeit von Religion. Gleichfalls erkennbar wird allerdings, dass unsere Erwartung hinsichtlich einer brückenbildenden Funktion der Vorurteile für dogmatisch-fundamentalistisch religiöse Menschen tragfähig ist (Scheepers et al. 2002, S. 256; These 5). Letztere weisen bei allen in der KONID-2019-Studie abgefragten gruppenbezogenen Vorurteile und Ressentiments höhere Zustimmungswerte auf. Dies trifft übrigens auch auf den Antisemitismus zu (gleichläufig im Ergebnis Middleton 1973, S. 44, 49). Am deutlichsten ist der Zusammenhang bei Homophobie und Muslimfeindlichkeit.

Um der brückenbildenden Funktion bestimmter Vorurteilsstrukturen noch exakter auf die Spur zu kommen, müsste man zukünftig komplexere Mediationsmodelle berechnen. Dies ist in Anbetracht der Länge des vorliegenden Aufsatzes und einer in den nutzbaren Daten vorliegenden Beschränkung hinsichtlich der notwendigen Abfragen von Sexismus, Antifeminismus und Transphobie nicht sinnvoll. Gleichwohl denken wir, mit den vorgelegten Ergebnissen die formulierten Thesen hinreichend bearbeitet zu haben und sagen zu können, dass das Verständnis von Religion und der eigenen Religiosität ein wichtiger Faktor für die Positionierung zu rechtsextremen bzw. rechten Überzeugungen ist - und Vorurteile die Brücke dorthin sind. 


\section{Fazit - Religionszugehörigkeit und Religiosität als Prädiktor rechtsextremer Einstellungen}

Die vorgelegten Ergebnisse beschreiben - trotz vielleicht noch bestehender Lücken in der Indikatorenbreite - eine beachtliche Relevanz von Religion für rechtsextreme Einstellungen. Es ist klar erkennbar: Die Ablehnung anderer Religionsgemeinschaften (z.B. des Islam oder des Judentums) fördert rechtsextreme Überzeugungen. Abneigungen gegenüber und Ängste vor anderen Religionsgemeinschaften werden in großen Teilen auf ihre Mitglieder (Muslim:innen, Jüd:innen) übertragen. Rechtsextremist:innen und auch Rechtspopulist:innen nutzen dabei bestehende und in der Bevölkerung teilweise weit verbreitete Vorurteile und Bedrohungsgefühle für sich. Diese richten sich gegen Muslim:innen und auch gegen Jüd:innen. Werden antisemitische Ressentiments mittlerweile sogar schon als fester Bestandteil einer rechtsextremen Haltung angesehen, hat sich die Ablehnung von Muslim:innen erst mit deren öffentlicher Sichtbarkeit manifestiert. Religionsgemeinschaften und ihre Mitglieder sind bewusster Zielpunkt rechtsextremer Handlungen und Überzeugungen. Rechtsextremist:innen bauen hierzu strategisch Feindbilder auf, z. B. indem sie Muslim:innen und Jüd:innen für gesellschaftliche Konflikte verantwortlich machen - bisweilen sogar in Kombination miteinander (siehe ,große Umvolkung“"). Damit instrumentalisieren sie in der Bevölkerung bestehende Ängste für sich und befördern diese Ängste gezielt durch den Aufbau von Narrativen und Propaganda (Wodak 2015).

Damit gilt heute wie früher die Annahme Theodor W. Adornos (1973) einer besonderen Stellung des Antisemitismus für den Rechtsextremismus. Und dieser Bezug gilt empirisch auch, wenn man die Konstrukte antisemitische Ressentiments und rechtsextreme Einstellungen trennt. Neben These 1, der Beförderung rechtsextremer Einstellungen durch antisemitische Ressentiments, ist auch Muslimfeindschaft eine wichtige Brücke zu rechtsextremen Einstellungen. Damit werden gruppenbezogene Vorurteile in der Bevölkerung über ihre Aktivierung seitens rechter Gruppen zu einer hochrelevanten „Einstiegsdroge“ (Decker und Brähler 2020, S. 17, 80) auf dem Weg hin zum Rechtsextremismus (These 6). Die Zuschreibung einer Bedrohung und Ängste vor einer Gruppe, was gerade gegenüber ,dem Islam“ der Fall ist, bestärken entlang des seitens der Integrated Threat Theory beschriebenen Mechanismus die Vorurteile und damit die geschilderte Gefahr (These 4).

Sind nun religiöse Menschen oder Christ:innen gegen solche Vorurteile immun? Den empirischen Ergebnissen nach wohl nicht. Mit Blick auf die Christ:innen macht weder die Zugehörigkeit zu einer Religionsgemeinschaft noch die persönliche Religiosität einen relevanten Unterschied für rechtsextreme Überzeugungen - weder im Sinne einer Immunisierung noch im Sinne einer Bestärkung. Doch so einfach ist es nicht (siehe Allport 1979). Ganz im Sinne von These 3 sind es spezifische religiöse Vorstellungen, die Nähe oder Distanz zu rechtsextremen Einstellungen bedingen (ähnlich Billiet 1995, S. 322). Ein dogmatisch-fundamentalistisches Verständnis der eigenen Religiosität kann durchaus zu einer Nähe zu rechtsextremen Positionen führen. Vorurteile und Ressentiments - z. B. gegenüber Muslim:innen und Jüd:innen - bringen dogmatische oder exklusivistische Christ:innen in eine Nähe zu rechtsextremen Einstellungen (These 5). Solche Positionen werden dann oft bei 
Kritik von dogmatischen Christ:innen als konservativ oder erhaltend und nicht als rechtsextrem deklariert. Selbst wenn man dieser Selbstbezeichnung in Teilen folgen will, stellen diese Vorurteile und Ressentiments doch Brückenköpfe zu rechtsextremen Überzeugungen dar. Dieser Gruppe von Christ:innen stehen Kirchenmitglieder und Christ:innen mit einem hohen sozialen Engagement und einer Offenheit für Pluralismus und andere Menschen gegenüber. Ihre vermutlich durch christliche Gemeinschaftswerte bestärkte Haltung ist Vorurteile ablehnend und damit rechtsextremistische Orientierungen zurückweisend. Auch interreligiöse Kontakte können als Hemmfaktor oder Gegenmobilisierung, z. B. bei in der Nähe von Kirchen angesiedelten Initiativen „gegen Rechts“, wirken. Gleichwohl kann die These 7 eines positiven Einflusses von Kontakten, wie es die Kontakthypothese vermutet, nicht vollständig bestätigt werden. $\mathrm{Zu}$ diesen christlich-religiösen Positionierungen tritt noch der eher neben den Volkskirchen angesiedelte Esoterikglauben. Er ist - ganz im Sinne der frühen Überlegungen Adornos (1973) - förderlich für rechtsextreme Haltungen (These 2; auch Huber und Yendell 2019). Mitentscheidend dürfte seine Offenheit für Verschwörungsmythen sein.

Die Wirkung von Religiosität ist somit ambivalent: Sie kann als Mediator sowohl hin zu einem starken Gegensatz gegenüber rechtsextremen Haltungen als auch zu einer Nähe oder Wahlverwandtschaft zu einzelnen Teilen rechtsextremistischer Überzeugungen führen (These 3). Vor allem sind es geteilte Vorurteile gegenüber Menschen mit nicht-binärer nicht-heterosexueller Geschlechtsorientierung und gegenüber Mitgliedern anderer Religionsgemeinschaften, die Gläubige in die Nähe rechtsextremer Einstellungen bringen. Auch Vorurteile gegenüber Ausländer:innen, Geflüchteten, Sinti:zze und Rom:nja sowie Frauen können als „Scharnier“ zu rechtsextremen Vorstellungswelten dienen. Dabei werden Geflüchtete, Migrant:innen und Muslim:innen im Zuschreibungsdenken oft miteinander verbunden (Pickel und Pickel 2019; Mudde 2019, S. 100-101; Steinmann 2020). Bei aller Deutlichkeit der Beziehungen ist anzumerken, dass der beschriebene Zusammenhang zwischen einer dogmatisch-fundamentalistischen Religionsauslegung und Rechtsextremismus nur für einen kleinen Teil der Christ:innen zutrifft, wie ja eine überzeugte rechtsextreme Einstellung auch nur unter wenigen Bundesbürger:innen greift. Gleichwohl kann man Annäherungen an bestimmte Einstellungen des rechten Spektrums nicht leugnen, vor allem, wenn sie noch zu keinem festgefassten rechtsextremen Weltbild wurden. Massiver noch als die Offenheit dogmatisch-fundamentalistischer Christ:innen für rechtsextreme Überzeugungen oder sie stützende Vorurteile ist der Nutzen von nichtchristlichen Religionsgemeinschaften als Feindbild des Rechtsextremismus. Speziell der von vielen Bürger:innen in Deutschland gefürchtete Islam und seine Mitglieder dienen Rechtsextremist:innen als Mobilisierungsfaktor für die eigene Sache. 
Anhang

Tab. 5 Übersicht über die verwendeten Datensätze

\begin{tabular}{|c|c|c|c|c|}
\hline Name der Studie & $N$ & Erhebungsmethode & $\begin{array}{l}\text { Erhebungs- } \\
\text { zeitraum }\end{array}$ & $\begin{array}{l}\text { Auswahl der Teil- } \\
\text { nehmenden }\end{array}$ \\
\hline $\begin{array}{l}\text { Allgemeine Bevöl- } \\
\text { kerungsumfrage der } \\
\text { Sozialwissenschaften } \\
\text { (ALLBUS) } 2018 \\
\text { und International } \\
\text { Social Survey Pro- } \\
\text { gramme (ISSP) 2018 } \\
\text { zu Religion }\end{array}$ & 1724 & $\begin{array}{l}\text { Persönlich-mündliche Be- } \\
\text { fragung mit standardisiertem } \\
\text { Frageprogramm (CAPI - } \\
\text { Computer Assisted Perso- } \\
\text { nal Interviewing); zwei Zu- } \\
\text { satzbefragungen als CASI } \\
\text { (Computer Assisted Self-In- } \\
\text { terviewing) im Rahmen des } \\
\text { ISSP (Splitverfahren) }\end{array}$ & $\begin{array}{l}\text { April- } \\
\text { September } \\
2018\end{array}$ & $\begin{array}{l}\text { Zweistufige, dispro- } \\
\text { portional geschich- } \\
\text { tete Zufallsauswahl } \\
\text { in Westdeutschland } \\
\text { (incl. West-Berlin) } \\
\text { und Ostdeutschland } \\
\text { (incl. Ost-Berlin) }\end{array}$ \\
\hline $\begin{array}{l}\text { Allgemeine Bevöl- } \\
\text { kerungsumfrage der } \\
\text { Sozialwissenschaften } \\
\text { (ALLBUS) } 2016\end{array}$ & 3490 & $\begin{array}{l}\text { Persönlich-mündliche Be- } \\
\text { fragung mit standardisiertem } \\
\text { Frageprogramm (CAPI - } \\
\text { Computer Assisted Perso- } \\
\text { nal Interviewing); zwei Zu- } \\
\text { satzbefragungen als CASI } \\
\text { (Computer Assisted Self-In- } \\
\text { terviewing) im Rahmen des } \\
\text { ISSP (Splitverfahren) }\end{array}$ & $\begin{array}{l}\text { April- } \\
\text { September } \\
2016\end{array}$ & $\begin{array}{l}\text { Zweistufige, dispro- } \\
\text { portional geschich- } \\
\text { tete Zufallsauswahl } \\
\text { in Westdeutschland } \\
\text { (incl. West-Berlin) } \\
\text { und Ostdeutschland } \\
\text { (incl. Ost-Berlin) }\end{array}$ \\
\hline $\begin{array}{l}\text { Bertelsmann Religi- } \\
\text { onsmonitor } 2017\end{array}$ & $\begin{array}{l}\text { Rund } \\
1500 \\
\text { (+ rund } \\
1000)\end{array}$ & $\begin{array}{l}\text { Primär standardisierte telefo- } \\
\text { nische Befragung, vereinzelt } \\
\text { persönliche Interviews }\end{array}$ & $\begin{array}{l}\text { Juli } \\
2016- \\
\text { März } \\
2017\end{array}$ & $\begin{array}{l}\text { Repräsentative Aus- } \\
\text { wahl (+ Sonder- } \\
\text { stichprobe unter } \\
\text { Muslim:innen) }\end{array}$ \\
\hline $\begin{array}{l}\text { Bertelsmann Religi- } \\
\text { onsmonitor } 2013\end{array}$ & 2005 & $\begin{array}{l}\text { Primär standardisierte telefo- } \\
\text { nische Befragung, vereinzelt } \\
\text { persönliche Interviews }\end{array}$ & $\begin{array}{l}\text { Ende } \\
2012\end{array}$ & $\begin{array}{l}\text { Repräsentative Aus- } \\
\text { wahl }\end{array}$ \\
\hline $\begin{array}{l}\text { Konfigurationen } \\
\text { individueller und } \\
\text { kollektiver religiöser } \\
\text { Identitäten und ihre } \\
\text { zivilgesellschaft- } \\
\text { lichen Potenziale } \\
\text { (KONID) } 2019\end{array}$ & $\begin{array}{l}2363 \\
(+500)\end{array}$ & Online- und Telefonbefragung & $\begin{array}{l}\text { Frühling } \\
\text { bis } \\
\text { Sommer } \\
2019\end{array}$ & $\begin{array}{l}\text { Bevölkerungs- } \\
\text { repräsentative } \\
\text { Hauptstichprobe } \\
\text { mit Überquotierung } \\
\text { junger Menschen } \\
\text { (+ Sonderstichprobe } \\
\text { unter türkeistämmi- } \\
\text { gen Muslim:innen) }\end{array}$ \\
\hline $\begin{array}{l}\text { Leipziger Autorita- } \\
\text { rismus Studie (LAS) } \\
2020\end{array}$ & 2503 & $\begin{array}{l}\text { Selbstausfüller mit Interview- } \\
\text { erbetreuung } \\
\text { (,Paper-Pencil“) }\end{array}$ & $\begin{array}{l}\text { Mai-Juni } \\
2020\end{array}$ & $\begin{array}{l}\text { Geschichtete } \mathrm{Zu}- \\
\text { fallsstichprobe }\end{array}$ \\
\hline $\begin{array}{l}\text { Leipziger Autorita- } \\
\text { rismus Studie (LAS) } \\
2018\end{array}$ & 2416 & $\begin{array}{l}\text { Selbstausfüller mit Interview- } \\
\text { erbetreuung } \\
\text { („Paper-Pencil“) }\end{array}$ & $\begin{array}{l}\text { Mai-Juli } \\
2018\end{array}$ & $\begin{array}{l}\text { Geschichtete } \mathrm{Zu} \text { - } \\
\text { fallsstichprobe }\end{array}$ \\
\hline
\end{tabular}




\section{Konstruktion der verwendeten Skalen}

Konstruktion Rechtsextremismus KONID 2019=Summierter Index (Likert-Skala) der Zustimmung zu den Items:

Im nationalen Interesse ist unter bestimmten Umständen eine Diktatur die bessere Staatsform; Eigentlich sind die Deutschen anderen Völker von Natur aus überlegen; Die Bundesrepublik ist durch die vielen Ausländer in einem gefährlichen Maß überfremdet; (Auch heute noch ist der Einfluss der Juden zu groß); Menschen, die wenig nützlich sind, kann sich keine Gesellschaft leisten.

Konstruktion Rechtsextremismus ALLBUS 2018= Summierter Index (Likert-Skala) der Zustimmung zu den Items:

Wir sollten endlich wieder Mut zu einem starken Nationalgefühl haben; Unter bestimmten Umständen ist eine Diktatur die bessere Staatsform; Der Nationalsozialismus hatte auch seine guten Seiten; (Ohne die Judenvernichtung würde man Hitler heute als einen großen Staatsmann ansehen); Deutschland ist durch die vielen Ausländer in einem gefährlichen Maß überfremdet; (Auch heute noch ist der Einfluss von Juden zu groß).

Konstruktion Rechtsextremismus LAS 2018: siehe Decker et al. (2013a); Decker et al. (2020, S. 35-36).

\section{\# Items in Klammern bei Korrelationsanalyse zu Antisemitismus ausgeschlossen aus Index.}

Antisemitismus ALLBUS $2018=$ Auch heute noch ist der Einfluss von Juden zu groß.

Muslimfeindlichkeit ALLBUS/ISSP 2018 = Wie ist Ihre Einstellung zu Menschen aus folgenden Religionsgruppen? Muslime

Ausländerfeindlichkeit ALLBUS 2018 = Deutschland ist durch die vielen Ausländer in einem gefährlichen Maß überfremdet.

Flüchtlingsfeindlichkeit ALLBUS 2018 = Der Zuzug von Flüchtlingen nach Deutschland sollte unterbunden werden.

Homophobie ALLBUS 2018 = Gleichgeschlechtliche Ehen sollten gesetzlich verboten sein.

Ablehnung Gleichstellungspolitik ALLBUS 2018 = Frauen sollten bei gleicher Eignung bei Bewerbungen und Beförderungen bevorzugt behandelt werden. (Ablehnung)

Subjektive Religiosität ALLBUS/ISSP 2018 = Als wie religiös würden Sie sich selbst beschreiben?

Rechts auf der Links-Rechts-Skala ALLBUS 2018 = Wenn Sie an Ihre eigenen politischen Ansichten denken, wo würden Sie diese Ansichten auf dieser Skala einstufen?

Gefühl fehlender politischer Wirkung ALLBUS 2018 = Die Politiker kümmern sich nicht viel darum, was Leute wie ich denken.

Wirtschaftliche Lage ALLBUS 2018 = Wie beurteilen Sie ganz allgemein die heutige wirtschaftliche Lage in Deutschland? 
Relative Deprivation ALLBUS 2018 = Und Ihre eigene wirtschaftliche Lage heute?

Soziales Vertrauen ALLBUS/ISSP $2018=$ Ganz allgemein, was meinen Sie: Kann man Menschen vertrauen oder kann man im Umgang mit Menschen nicht vorsichtig genug sein?

Glaube an einen persönlichen Gott ALLBUS/ISSP $2018=$ Es gibt einen Gott, der sich persönlich mit jedem Menschen befasst.

Öffentliche religiöse Praxis ALLBUS 2018 = Wie oft gehen Sie im Allgemeinen in die Kirche?/Wie oft gehen Sie im Allgemeinen in die Kirche - bzw. in die Moschee, Synagoge oder ein anderes Gotteshaus?

Soziale Religiosität ALLBUS 2018 = Eine Religion im Alltag zu praktizieren, hilft den Menschen Freundschaften zu schließen.

Esoterik ALLBUS/ISSP 2018 = Es gibt Wahrsager, die die Zukunft wirklich voraussehen können.

Konfession ALLBUS 2018 = Darf ich Sie fragen, welcher Religionsgemeinschaft Sie angehören?

Alter ALLBUS $2018=$ Berechnung aus dem Geburtsjahr des/der Befragten

Bildung (niedrig) ALLBUS $2018=$ Frage nach dem Schulabschluss

Geschlecht ALLBUS 2018 = Interviewer:in trägt das Geschlecht der befragten Person ohne Befragen ein.

Ausländerfeindlichkeit KONID 2019 = Die Bundesrepublik ist durch die vielen Ausländer in einem gefährlichen Maß überfremdet.

Muslimfeindlichkeit KONID 2019 = Muslimen sollte die Zuwanderung nach Deutschland untersagt werden.

Flüchtlingsfeindlichkeit KONID 2019 = Die Zuwanderung von Asylbewerbern nach Deutschland sollte grundsätzlich unterbunden werden.

Antiziganismus KONID 2019 = Sinti und Roma sollten aus den Innenstädten entfernt werden.

Primärer Antisemitismus KONID $2019=$ Auch heute noch ist der Einfluss der Juden zu groß.

Israelbezogener Antisemitismus KONID 2019 = Durch die israelische Politik werden mir die Jüdinnen und Juden immer unsympathischer.

Homophobie KONID 2019 = Eine sexuelle Beziehung zwischen Personen desselben Geschlechts ist unnatürlich.

Ablehnung von Gleichstellungspolitik KONID $2019=$ Maßnahmen zur Antidiskriminierung von Lesben, Schwulen, Bisexuellen, Transgender, Intersexuellen und Queers sind unnötig.

Nationaler Chauvinismus KONID 2019 = Eigentlich sind die Deutschen anderen Völker von Natur aus überlegen.

Selbstbeschreibung als religiös KONID $2019=$ Selbstdeklaration Religiosität

Öffentliche religiöse Praxis KONID 2019 = Frage nach dem Besuch von Gotteshäusern

Konfession: evangelisch (Ref.: Konfessionslose), Konfession: katholisch (Ref.: Konfessionslose), Konfession: andere Religionsgemeinschaften (Ref.: Konfessionslose) KONID 2019 = Frage nach der subjektiven Religionszugehörigkeit 
Kombination der eigenen Religiosität mit sozialem Engagement KONID 2019 = Additiver Index der Intensität des Engagements in der Gemeinde. Bestehend aus: Betreuung und Seelsorge, Sozialarbeit und entsprechende Seelsorge, Bildung, Glaubens- und Traditionsvermittlung, Gesellschaftsbezogene Bildung, Frauen- und Männerarbeit, Interreligiöser Bereich, Kinder- und Jugendarbeit, Seniorenarbeit und -betreuung, Leitung, Mission \& Entwicklungshilfe, Gesang \& Musik, Unterstützung und Organisation religiöser Feiern, Öffentlichkeitsarbeit, Leitung religiöser Feiern

Dogmatisch-fundamentalistische Auslegung der eigenen Religion KONID $2019=$ Religion sollte die einzige und letztgültige politische Autorität sein, Die Regeln und Werte meiner Religion haben im Konfliktfall Vorrang vor der Deutschen Verfassung, Ich wäre bereit meine religiösen Überzeugungen auch mit Gewalt durchzusetzen, Es gibt nur eine wahre Religion.

Liberale Auslegung der eigenen Religion KONID 2019 = Frage nach der Auslegung der eigenen Religion. Skala reicht von $1=$ sehr konservativ bis $6=\operatorname{sehr}$ liberal

Autoritarismus KONID $2019=\mathrm{Zu}$ den wichtigsten Eigenschaften, die jemand haben kann, gehört disziplinierter Gehorsam der Autorität gegenüber.

Gefühl fehlender politischer Wirkung KONID $2019=$ Leute wie ich haben so oder so keinen Einfluss darauf, was die Regierung tut.

Befragte(r) sieht sich als Verlierer:in in der Gesellschaft KONID $2019=$ Wenn ich mir mein Leben anschaue, fühle ich mich eher als Verlierer/in in der Gesellschaft.

Befragte(r) fühlt sich depriviert KONID 2019 = Unabhängig davon, wie gerecht es in unserer Gesellschaft zugeht. Glauben Sie, dass Sie bekommen, was Ihnen gerechterweise zusteht? Bekommen Sie mehr als Ihnen zusteht? Oder haben Sie das Gefühl, dass Sie nicht bekommen, was Ihnen zusteht? Ich bekomme ... ( 1 = viel oder etwas mehr als mir gerechterweise zustehen würde, $4=$ sehr viel weniger als mir gerechterweise zustehen würde)

Eigene wirtschaftliche Lage wird als schlecht bewertet KONID 2019 = Frage nach der persönlichen wirtschaftlichen Lage. Skala reicht von $1=\operatorname{sehr}$ gut bis $4=$ sehr schlecht

Rechts auf der Links-Rechts-Skala KONID 2019 = In der Politik spricht man oft von ,links“ und ,rechts“. Wo auf einer Skala von 0-10 würden Sie sich selbst einstufen, wenn 0 für links steht und 10 für rechts?

Wohnsitz in Westdeutschland KONID 2019 = Zuordnung auf Grundlage des Bundeslandes

Wohnsitz in einer Großstadt KONID $2019=$ Urbanität Wohnort

Bildung (hoch) KONID 2019 = Frage nach dem Bildungsabschluss

Geschlecht KONID 2019 = Frage nach dem Geschlecht

Alter KONID 2019 = Berechnung aus dem Geburtsjahr des/der Befragten

Funding Open Access funding enabled and organized by Projekt DEAL.

Open Access Dieser Artikel wird unter der Creative Commons Namensnennung 4.0 International Lizenz veröffentlicht, welche die Nutzung, Vervielfältigung, Bearbeitung, Verbreitung und Wiedergabe in jeglichem Medium und Format erlaubt, sofern Sie den/die ursprünglichen Autor(en) und die Quelle ordnungsgemäß nennen, einen Link zur Creative Commons Lizenz beifügen und angeben, ob Änderungen vorgenommen wurden. 
Die in diesem Artikel enthaltenen Bilder und sonstiges Drittmaterial unterliegen ebenfalls der genannten Creative Commons Lizenz, sofern sich aus der Abbildungslegende nichts anderes ergibt. Sofern das betreffende Material nicht unter der genannten Creative Commons Lizenz steht und die betreffende Handlung nicht nach gesetzlichen Vorschriften erlaubt ist, ist für die oben aufgeführten Weiterverwendungen des Materials die Einwilligung des jeweiligen Rechteinhabers einzuholen.

Weitere Details zur Lizenz entnehmen Sie bitte der Lizenzinformation auf http://creativecommons.org/ licenses/by/4.0/deed.de.

\section{Literatur}

Adorno, Thomas. 1973. Studien zum autoritären Charakter. Frankfurt/Main: Suhrkamp.

Adorno, Theodor W. 2020. Minima Moralia. Reflections from damaged life. London: Verso Books.

Allport, Gordon W. 1979. The nature of prejudice. New York: Perseus.

Allport, Gordon W., und Michael J. Ross. 1967. Personal religious orientation and prejudice. Journal of Personality and Social Psychology 5(4):432-443.

Altemeyer, Bob, und Bruce Hunsberger. 1992. Authoritarianism, Religious Fundamentalism, Quest, and Prejudice. International Journal for the Psychology of Religion 2(2):113-133.

Arzheimer, Kai. 2008. Die Wähler der extremen Rechten 1980-2002. Wiesbaden: VS.

Arzheimer, Kai. 2019. "Don't mention the war!" How populist right-wing radicalism became (almost) normal in Germany. Journal of Common Market Studies 57:90-102.

Arzheimer, Kai, und Elisabeth Carter. 2009. Christian religiosity and voting for west European radical right parties. West European Politics 32(5):985-1011.

Backes, Uwe, und Eckhard Jesse. 1995. Jahrbuch Extremismus und Demokratie. Baden-Baden: nomos Verlag.

Backes, Uwe, und Steffen Kailitz. 2020. Sachsen - Eine Hochburg des Rechtsextremismus? Göttingen: Vandenhoeck \& Ruprecht.

Bednarz, Liane. 2018. Die Angstprediger. Wie rechte Christen Gesellschaft und Kirchen unterwandern. München: Droemer.

Beyer, Heiko, und Annette Schnabel. 2019. The entanglement of religion and politics in Europe. How and why religious and political worldviews merge in times of uncertainty. Interdisciplinary Journal of Research on Religion 15:1-27.

Billiet, Jaak. 1995. Church involvement, ethnocentrism, and voting for a radical right-wing party: diverging behavioral outcomes of equal attitudinal dispositions. Sociology of Religion 56(3):303-326.

Billiet, Jaak, Ann Carton, und Rob Eisinga. 1995. Contrasting effects of church involvement on the dimensions of ethnocentrism: an empirical study among flemish catholics. Social Compass 42(1):97-107.

Blalock, Hubert M. 1967. Toward a Theory of Minority-Group Relations. Richard: Dennis Publications.

Blumer, Herbert. 1958. Race Prejudice as a Sense of Group Position. The Pacific Sociological Review 1(1):3-7.

Butter, Michael. 2018. „Nichts ist, wie es scheint“. Über Verschwörungstheorien. Frankfurt/Main: Suhrkamp.

Decker, Oliver, und Elmar Brähler. 2006. Vom Rand zur Mitte. Rechtsextreme Einstellungen und ihre Einflussfaktoren in Deutschland. Berlin: FES. Unter Mitarbeit von Norman Geissler.

Decker, Oliver, und Elmar Brähler (Hrsg.). 2018. Flucht ins Autoritäre: Rechtsextreme Dynamiken in der Mitte der Gesellschaft. Gießen: Psychosozial.

Decker, Oliver, und Elmar Brähler (Hrsg.). 2020. Autoritäre Dynamiken. Alte Ressentiments - neue Radikalität. Gießen: Psychosozial.

Decker, Oliver, Johannes Kiess, und Elmar Brähler (Hrsg.). 2013a. Rechtsextremismus der Mitte. Eine sozialpsychologische Gegenwartsanalyse. Gießen: Psycholozial-Verlag.

Decker, Oliver, Andreas Hinz, Norman Geißler, und Elmar Brähler. 2013b. Fragebogen zur rechtsextremen Einstellung - Leipziger Form. In Rechtsextremismus der Mitte. Eine sozialpsychologische Gegenwartsdiagnose, Hrsg. Oliver Decker, Johannes Kiess, und Elmar Brähler, 197-212. Gießen: Psychosozial.

Decker, Oliver, Johannes Kiess, und Elmar Brähler (Hrsg.). 2016. Die enthemmte Mitte. Autoritäre und rechtsextreme Einstellung in Deutschland. Die Leipziger „Mitte“-Studie 2016. Gießen: PsychosozialVerlag. 
Decker, Oliver, Johannes Kiess, und Elmar Brähler. 2018. Antisemitische Ressentiments in Deutschland: Verbreitung und Ursachen. In Flucht ins Autoritäre. Rechtsextreme Dynamiken in der Mitte der Gesellschaft, Hrsg. Oliver Decker, Elmar Brähler, 179-216. Gießen: Psychosozial.

Decker, Oliver, Johannes Kiess, Julia Schuler, Barbara Handke, Gert Pickel, und Elmar Brähler. 2020. Die Leipziger Autoritarismus Studie 2020: Methode, Ergebnisse und Langzeitverlauf. In Autoritäre Dynamiken. Alte Ressentiments - neue Radikalität, Hrsg. Oliver Decker, Elmar Brähler, 27-88. Gießen: Psychosozial.

Diekmann, Isabell. 2017. Islamfeindlichkeit oder MuslimInnenfeindlichkeit? Empirische Datenanalyse zur Differenzierung zweier Phänomene. IKG Working Paper 12:1-46. Bielefeld: IKG.

Falter, Jürgen, und Markus Klein. 1994. Wer wählt rechts? Die Wähler und Anhänger rechtsextremistischer Parteien im vereinigten Deutschland. München: Beck.

Fulton, Aubyn, Richard Gorsuch, und Elisabeth Maynard. 1999. Religious orientation, antihomosexual sentiment, and fundamentalism among christians. Journal for the Scientific Study of Religion 38(1):14-22.

Gurr, Ted Robert. 1973. The Revolution. Social-Change Nexus: Some Old Theories and New Hypotheses. Comparative Politics 5(3):359-392.

Hayes, Andrew F. 2017. Introduction to mediation, moderation, and conditional process analysis. A regression-based approach. New York: Guilford.

Haynes, Jeffrey. 2021. Trump and the Politics of Neo-Nationalism. The Christian Right and Secular Nationalism in America. London: Routledge.

Heilbronn, Christian, Doron Rabinovici, und Natan Sznaider. 2019. Neuer Antisemitismus? Fortsetzung einer globalen Debatte. Frankfurt/Main: Suhrkamp.

Heitmeyer, Wilhelm. 1992. Die Bielefelder Rechtsextremismus-Studie. Erste Langzeituntersuchung zur politischen Sozialisation männlicher Jugendlicher. Weinheim: Juventa.

Hjerm, Mikael. 2007. Do numbers really count? Group threat theory revisited. Journal of Ethnic and Migration Studies 33(8):1253-1275. https://doi.org/10.1080/13691830701614056.

Höcker, Charlotte, Gert Pickel, und Oliver Decker. 2020. Antifeminismus - das Geschlecht im Autoritarismus? Die Messung von Antifeminismus und Sexismus in Deutschland auf der Einstellungsebene. In Autoritäre Dynamiken. Alte Ressentiments - neue Radikalität, Hrsg. Oliver Decker, Elmar Brähler, 249-282. Gießen: Psychosozial.

Huber, Stefan, und Alexander Yendell. 2019. Does Religiosity Matter? Explaining right-wing extremist attitudes and the vote for the Alternative for Germany (AfD). Religion and Society in Central and Eastern Europe 12(1):63-87.

Jaschke, Hans-Gerd. 2001. Rechtsextremismus und Fremdenfeindlichkeit: Begriffe, Positionen, Praxisfelder, 2. Aufl., Wiesbaden: VS.

Johnson, Megan, Wade C. Rowatt, Lucy M. Barnard-Brak, Julie A. Patock-Peckham, Jordan P. LaBouff, und Robert D. Carlisle. 2011. A mediational analysis of the role of right-wing authoritarianism and religious fundamentalism in the religiosity-prejudice link. Personality and Individual Differences 50:851-856.

Jörke, Dirk, und Veith Selk. 2017. Theorien des Populismus. Zur Einführung. Hamburg: Junius.

Kailitz, Steffen. 2004. Politischer Extremismus in der Bundesrepublik Deutschland. Eine Einführung. Wiesbaden: VS.

Kiess, Johannes, Oliver Decker, und Elmar Brähler. 2015. Was ist rechtsextreme Einstellung, und woraus besteht sie? Bonn: Bundeszentrale für politische Bildung. https://www.bpb.de/politik/extremismus/ rechtsextremismus/198945/was-ist-rechtsextreme-einstellung-und-woraus-besteht-sie.

Kiess, Johannes, Oliver Decker, Ayline Heller, und Elmar Brähler. 2020. Antisemitismus als antimodernes Ressentiment: Struktur und Verbreitung eines Weltbildes. In Autoritäre Dynamiken. Alte Ressentiments - neue Radikalität, Hrsg. Oliver Decker, Elmar Brähler, 211-248. Gießen: Psychosozial.

Küpper, Beate, und Andreas Zick. 2006. Riskanter Glaube. Religiosität und Abwertung. In Deutsche Zustände. Folge 4, Hrsg. Wilhelm Heitmeyer, 179-188. Frankfurt am Main: Suhrkamp.

Küpper, Beate, und Andreas Zick. 2010. Religion and Prejudice in Europe. New empirical findings. London: Alliance Publishing Trust.

Küpper, Beate, und Andreas Zick. 2017. Religion und Menschenfeindlichkeit. In Religiosität: Die Dunkle Seite: Beiträge zur empirischen Religionsforschung, Hrsg. Christian Zwingmann, Constantin Klein, und Florian Jeserich, 117-137. Münster: Waxmann.

Lenski, Georg. 1963. The religious factor A sociological study of religion's impact on politics, economics, and family life. Garden City: Doubleday.

Lesch, Walter (Hrsg.). 2017. Christentum und Populismus. Freiburg: Herder. 
Liedhegener, Antonius. 2018. Pluralisierung. In Handbuch Religionssoziologie, Hrsg. Volkhard Krech, Detlef Pollack, Markus Hero, Olaf Müller, 347-382. Wiesbaden: Springer VS.

Liedhegener, Antonius, Gert Pickel, Anastas Odermatt, Alexander Yendell, und Yvonne Jaeckel. 2019. Wie Religion ,uns“ trennt - und verbindet: Befunde einer Repräsentativbefragung zur gesellschaftlichen Rolle von religiösen und sozialen Identitäten in Deutschland und der Schweiz 2019 (Forschungsbericht). Luzern/Leipzig.

Lienesch, Michael. 1982. Right-wing religion: Christian conservatism as a political movement. Political Science Quarterly 97(3):403-425.

Lipset, Seymour M. 1981. Political man: the social bases of politics. Baltimore: Johns Hopkins.

Lipstadt, Deborah. 2019. Antisemitism. Here and now. London: Scribe.

Lühmann, Michael. 2020. https://www.deutschlandfunknova.de/beitrag/evangelikale-christen-und-derbible-belt-verbindungen-zu-pegida-und-zur-afd. Zugegriffen am 11.07.2021.

Marzouki, Nadia, Duncan McDonell, und Oliver Roy. 2016. Saving the people. How populists hijack religion. Oxford: Oxford University Press.

Middleton, Russell. 1973. Do Christian beliefs cause anti-semitism? American Sociological Review 38(1):33-52.

Minkenberg, Michael. 2000. The renewal of the radical right: between modernity and anti-modernity. Government and Opposition 35(2):170-188.

Minkenberg, Michael. 2011. The radical right in Europe. Gütersloh: Bertelsmann.

Moghaddam, Fathali, und Vuk Vuksanovic. 1990. Attitudes and behavior towards human rights. Across different contexts: the role of right-wing authoritarianism, political ideology, and religiosity. Journal of Psychology 25:455-474.

Mudde, Cas. 2019. The far right today. Cambridge: Cambridge University Press.

Mudde, Cas, und Cristóbal Rovira Kaltwasser. 2017. Populism. A very short introduction. Oxford/New York: Oxford University Press.

Neureiter, Marcus. 1996. Rechtsextremismus im vereinigten Deutschland. Eine Untersuchung sozialwissenschaftlicher Deutungsmuster und Erklärungsansätze. Marburg: Tectum.

Norris, Pippa. 2005. Radical right. Voters and parties in the electoral market. Cambridge: Cambridge University Press.

Öztürk, Cemal, und Gert Pickel. 2019. Islamophobic right-wing populism? Empirical insights about citizen's susceptibility to Islamophobia and its impact on right-wing populist's electoral sucess. Eastern Europe in a comparative perspective. Religion and Society in Central and Eastern Europe 12(1):39-62.

Öztürk, Cemal, und Gert Pickel. 2021. Eine Stimme gegen die Invasion der Muslim*innen? Zur Bedeutung muslim*innenfeindlicher Einstellungen für die Mobilisierungserfolge und den machtpolitischen Aufstieg rechtspopulistischer Parteien in Europa. In Populismus an der Macht. Strategien und Folgen populistischen Regierungshandelns, Hrsg. Wolfgang Muno, Christian Pfeiffer, 61-100. Wiesbaden: Springer VS.

Pettigrew, Thomas F. 1998. Intergroup contact theory. Annual Review of Psychology 49:65-85.

Pettigrew, Thomas F., und Linda Tropp. 2006. A meta-analytic test of intergroup contact theory. Journal of Personality and Social Psychology 90(5):751-783.

PEW Research Institute. 2018. Being Christian in western Europe. New York: PEW Research Institute.

Pfahl-Traughber, Armin. 2019. Rechtsextremismus. Eine kritische Bestandsaufnahme nach der Wiedervereinigung, 3. Aufl., Wiesbaden: Springer VS.

Pickel, Gert. 2018. Religion als Ressource für Rechtspopulismus? Zwischen Wahlverwandtschaften und Fremdzuschreibungen. Zeitschrift für Religion, Gesellschaft und Politik 2(2):277-312. https://doi.org/ 10.1007/s41682-018-0032-z.

Pickel, Gert. 2019a. Weltanschauliche Vielfalt und Demokratie. Wie sich religiöse Vielfalt auf die Demokratie auswirkt. Gütersloh: Bertelsmann Stiftung.

Pickel, Susanne. 2019b. Die Wahl der AfD. Frustration, Deprivation, Angst oder Wertekonflikt? In Die Bundestagswahlen 2017, Hrsg. Karl-Rudolf Korte. Wiesbaden: Springer VS.

Pickel, Gert, und Oliver Decker. 2016. Extremismus in Sachsen. Eine kritische Bestandsaufnahme. Leipzig: Edition Leipzig.

Pickel, Gert, und Cemal Öztürk. 2018. Islamophobia without muslims? The 'contact hypothesis' as an explanation for anti-muslim attitudes - eastern European societies in a comparative perspective. Journal of Nationalism, Memory \& Language Politics 12(2):162-191.

Pickel, Gert, und Cemal Öztürk. 2020. The varying challenge of Islamophobia for the EU: on anti-muslim resentments and its dividend for right-wing populists and Eurosceptics-central and eastern europe 
in a comparative perspective. In Illiberal trends and anti-EU politics in east central Europe, Hrsg. Astrid Lorenz, Lisa H. Anders, 57-80. Cham: Palgrave.

Pickel, Susanne, und Gert Pickel. 2018a. Empirische Politikforschung. Einführung in die Methoden der Politikwissenschaft. München: De Gruyter/Oldenbourg.

Pickel, Gert, und Susanne Pickel. 2018b. Migration als Gefahr für die politische Kultur? Kollektive Identitäten und Religionszugehörigkeit als Herausforderung demokratischer Gemeinschaften. Zeitschrift für Vergleichende Politikwissenschaft (ZfVP) 12(1):297-320. Special Issue: Migration und Integration als politische Herausforderung - Vergleichende Analysen zu politisch-kulturellen Voraussetzungen der Migrationspolitik und Reaktionen.

Pickel, Gert, und Susanne Pickel. 2019. Der Flüchtling als Muslim - und unerwünschter Mitbürger? In Flucht und Migration in Europa. Neue Herausforderungen für Parteien, Kirchen und Religionsgemeinschaften, Hrsg. Oliver Hidalgo, Gert Pickel, 279-324. Wiesbaden: Springer VS.

Pickel, Gert, und Alexander Yendell. 2016. Islam als Bedrohung? Beschreibung und Erklärung von Einstellungen zum Islam im Ländervergleich. Zeitschrift für Vergleichende Politikwissenschaft 10(3-4):273-309.

Pickel, Gert, und Alexander Yendell. 2018. Religion als konfliktärer Faktor in Zusammenhang mit Rechtsextremismus, Muslimfeindschaft und AfD-Wahl. In Flucht ins Autoritäre. Rechtsextreme Dynamiken in der Mitte der Gesellschaft, Hrsg. Oliver Decker, Elmar Brähler, 217-243. Gießen: Psychosozial.

Pickel, Gert, und Alexander Yendell. 2021. Islam- und Muslimfeindlichkeit in Sachsen: Ein Problem für die Integration von muslimischen Zuwanderern und den gesellschaftlichen Zusammenhalt? In Sachsen zwischen Integration und Desintegration. Politisch-kulturelle Heimaten, Hrsg. Steffen Kailitz, Gert Pickel, und Tobias Genswein, 165-184. Wiesbaden: Springer VS.

Pickel, Gert, Alexander Yendell, und Yvonne Jaeckel. 2016. Religiöse Pluralität als Bedrohung oder kulturelle Bereicherung? Die Wahrnehmung von Bedrohung durch Religion im Ländervergleich. In $R e$ ligiöse Identitäten in politischen Konflikten, Hrsg. Ines-Jacqueline Werkner, Oliver Hidalgo, 83-123. Wiesbaden: Springer VS.

Pickel, Gert, Immo Fritsche, Holger Lengfeld, Oliver Decker, Annedore Hoppe, und Alexander Yendell. 2020a. Gesellschaftlicher Zusammenhalt und Rechtspopulismus in der empirischen Forschung. In Gesellschaftlicher Zusammenhalt. Ein interdisziplinärer Dialog, Hrsg. Nicole Deitelhoff, Olaf GrohSamberg, und Matthias Middell, 218-245. Frankfurt/Main: Campus.

Pickel, Gert, Kazim Celik, Julia Schuler, und Oliver Decker. 2020b. Bedrohungsempfinden als Quelle gruppenbezogener Vorurteile durch Religionen in einer heterogenen Stadtgesellschaft. Analysen des Berlinmonitors. Zeitschrift für Religion, Gesellschaft und Politik 4(1):7-43.

Pickel, Gert, Antonius Liedhegener, Yvonne Jaeckel, Anastas Odermatt, und Alexander Yendell. 2020c. Religiöse Identitäten und Vorurteile in Deutschland und der Schweiz - Konzeptionelle Überlegungen und empirische Befunde. Zeitschrift für Religion, Gesellschaft und Politik 4(1):149-196.

Pickel, Gert, Susanne Pickel, und Alexander Yendell. 2020d. Zersetzungspotentiale einer demokratischen politischen Kultur: Verschwörungstheorien und erodierender gesellschaftlicher Zusammenhalt. In Autoritäre Dynamiken. Leipziger Autoritarismus Studie 2020, Hrsg. Oliver Decker, Elmar Brähler, 89-118. Gießen: Psychosozial.

Pollack, Detlef, Olaf Müller, Gergely Rosta, Nils Friedrichs, und Alexander Yendell (Hrsg.). 2014. Wahrnehmung und Akzeptanz religiöser Vielfalt in Europa. Wiesbaden: Springer VS.

Priester, Karin. 2007. Populismus. Historische und aktuelle Erscheinungsformen. Frankfurt: Campus.

Priester, Karin. 2012. Rechter und linker Populismus. Annäherung an ein Chamäleon. Frankfurt: Campus.

Quent, Matthias. 2019. Deutschland rechts Außen. Wie die Rechten nach der Macht greifen und wie wir sie stoppen können. München: Piper.

Quillian, Lincoln. 1995. Prejudice as a Response to Perceived Group Threat: Population Composition and Anti-Immigrant and Racial Prejudice in Europe. American Sociological Review 60: 586-611.

Rebenstorf, Hilke. 2018. „Rechte“ Christen? - Empirische Analysen zur Affinität christlich-religiöser und rechtspopulistischer Positionen. Zeitschrift für Religion, Gesellschaft und Politik https://doi.org/10. 1007/s41682-018-0024-z.

Rippl, Susanne, und Christian Seipel. 2018. Modernisierungsverlierer, Cultural Backlash, Postdemokratie. Was erklärt rechtspopulistische Orientierungen? Kölner Zeitschrift für Soziologie und Sozialpsychologie https://doi.org/10.1007/s11577-018-0522-1.

Roof, Wade Clark. 1974. Religious orthodoxy and minority prejudice: causal relationship or reflection of Localistic world view? American Journal of Sociology 80:643-664.

Rydgren, Jens. 2018. The Oxford handbook of the radical right. Oxford: Oxford University Press.

Salzborn, Samuel. 2014. Antisemitismus. Geschichte, Theorie, Empirie. Baden-Baden: Nomos. 
Salzborn, Samuel. 2015. Rechtsextremismus. Erscheinungsformen und Erklärungsansätze, 2. Aufl., BadenBaden: Nomos.

Scheepers, Peer, Mérove Gijsberts, und Evelyn Hello. 2002. Religiosity and prejudice against ethnic minorities in europe: cross-national tests on a controversial relationship. Review of Religious Research 43(3):242-265.

Scheuch, Erwin, und Hans-Dieter Klingemann. 1967. Theorie des Rechtsradikalismus in westlichen Industriegesellschaften. Hamburger Jahrbuch für Wirtschafts- und Gesellschaftspolitik 12:11-29.

Schließler, Clara, Nele Hellweg, und Oliver Decker. 2020. Aberglaube, Esoterik und Verschwörungsmentalität in Zeiten der Pandemie. In Autoritäre Dynamiken. Alte Ressentiments - neue Radikalität, Hrsg. Oliver Decker, Elmar Brähler, 283-309. Gießen: Psychosozial.

Schönfeld, Anne. 2018. Forschungszugänge zum Themenfeld: Islam-/Muslimfeindlichkeit und antimuslimischer Rassismus. Eine Bestandsaufnahme. Essen: MUTIK.

von Schurbein, Stefanie. 1992. Religion als Kulturkritik. Neugermanisches Heidentum im 20. Jahrhundert. Heidelberg: Carl Winter Universitätsverlag.

Shooman, Yasemin. 2014. „...weil ihre Kultur so ist“ Narrative des antimuslimischen Rassismus. Bielefeld: transcript.

Spielhaus, Riem. 2018. Zwischen Migrantisierung von Muslimen und Islamisierung von Migranten. In Postmigrantische Perspektiven: Ordnungssysteme, Repräsentationen, Kritik, Hrsg. Naika Foroutan, Juliane Karakayali, und Riem Spielhaus, 129-143. Frankfurt/M.: Campus.

Spier, Tim. 2010. Modernisierungsverlierer? Die Wählerschaft rechtspopulistischer Parteien in Westeuropa. Wiesbaden: Springer VS.

Steinmann, Jan-Philip. 2020. Religiosity and natives social contact with new refugees. Explaining differences between East and West Germany. International Journal of Intercultural Relations 74:189-205.

Stephan, Walter G., und Lausanne C. Renfro. 2016. The role of threat in intergroup relations. In From prejudice to intergroup emotions: differentiated reactions to social groups, Hrsg. Diane M. Mackie, Elliot R. Smith, 191-207. New York: Psychology Press.

Stephan, Walter G., und C. Lausanne Renfro. 2002. The Role of Threat in Intergroup Relations. In From Prejudice to Intergroup Emotions, Hrsg. Diana M. Mackie und Eliot R. Smith, 191-208. New York/ Hove, UK: Psychology Press.

Stephan, Walter S., und Cookie White Stephan. 2000. An integrated threat theory of prejudice. In Reducing prejudice and discrimination, Hrsg. Stuart Oskamp, 23-45. Mahwah: Erlbaum.

Strabac, Zan, und Ola Listhaug. 2007. Anti-Muslim prejudice in Europe: a multilevel analysis of survey data from 30 countries. Social Science Research 37:268-286.

Strube, Sonja Angelika. 2015. Rechtsextremismus als Herausforderung für die Theologie. Freiburg, Basel, Wien: Herder.

Taggart, Paul. 2000. Populism. Buckingham: Open University Press.

Tajfel, Henri. 1982. Social identity and intergroup relations. Cambridge: University Press.

Tajfel, Henri, und John C. Turner. 1986. The social identity theory of intergroup behavior. In The social psychology of intergroup relations, Hrsg. Stephan Worchel, William Austin, 7-24. Chicago: NelsonHall.

Triandafyllidou, Anna. 1998. National identity and the 'other. Ethnic and Racial Studies 21(4):593-612. https://doi.org/10.1080/014198798329784.

Uenal, Fatith. 2016. Disentangling Islamophobia: The Differential Effects of Symbolic, Realistic, and Terroristic Threat Perceptions as Mediators Between Social Dominance Orientation and Islamophobia. Journal of Social and Political Psychology 4(1):66-90.

Urbinati, Nadia. 2019. Me the people. How populism transform democracy. Cambridge: Harvard University Press.

Virchow, Fabian. 2016. Rechtsextremismus: Begriffe - Forschungsfelder - Kontroversen. In Handbuch Rechtsextremismus, Hrsg. Fabian Virchow, Martin Langebach, und Alexander Häußler, 5-42. Wiesbaden: Springer VS.

Virchow, Fabian, Martin Langebach, und Alexander Häußler. 2016. Handbuch Rechtsextremismus. Wiesbaden: Springer VS.

Voegelin, Eric. 1938. Die politischen Religionen. Stockholm: Bermann-Firscher.

Wiedemann, Felix. 2016. Das Verhältnis der extremen Rechten zur Religion. In Handbuch Rechtsextremismus, Hrsg. Fabian von Virchow, Martin Langebach, und Alexander Häußler, 511-532. Wiesbaden: Springer VS.

Wodak, Ruth. 2015. Politik mit der Angst. Zur Wirkung rechtspopulistischer Diskurse. Wien: Edition Konturen. 
Yendell, Alexander. 2014. Warum die Bevölkerung Ostdeutschlands gegenüber Muslimen ablehnender eingestellt ist als die Bevölkerung Westdeutschlands. In Grenzen der Toleranz, Hrsg. Detlef Pollack, Olaf Müller, Gergely Rosta, Nils Friedrichs, und Alexander Yendell, 59-78. Wiesbaden: Springer.

Yendell, Alexander, und Stefan Huber. 2020. Negative views of Islam in Switzerland with special regard to religiosity as an explanatory factor. Zeitschrift für Religion, Gesellschaft und Politik 4(1):81-104.

Yendell, Alexander, und Gert Pickel. 2019. Islamophobia and anti-Muslim feeling in Saxony-theoretical approaches and empirical findings based on population surveys. Journal of Contemporary European Studies https://doi.org/10.1080/14782804.2019.1680352.

Zick, Andreas, und Beate Küpper. 2016. Rechtsextreme und menschenfeindliche Einstellungen. In Handbuch Rechtsextremismus, Hrsg. Fabian Virchow, Martin Langebach, und Alexander Häußler, 115-135. Wiesbaden: Springer VS.

Zick, Andreas, Beate Küpper, und Wilhelm Berghan. 2019. Verlorene Mitte - Feindselige Zustände. Rechtsextreme Einstellungen in Deutschland 2018/19. Bonn: Dietz. 